\title{
Purification and characterization of antibacterial surfactin isoforms produced by Bacillus velezensis SK
}

\author{
Sagar S. Barale ${ }^{1}$, Savaliram G. Ghane ${ }^{3}$ and Kailas D. Sonawane ${ }^{1,2^{*}}$ (])
}

\begin{abstract}
Bacillus velezensis SK having broad-spectrum antimicrobial activity has been isolated from soil. The efficient extraction of antimicrobial compounds produced in various mediums has been done using Diaion HP-20 resin. Further, characterization of an antimicrobial compound by TLC, FTIR, in-situ bioautography analysis revealed the presence of cyclic lipopeptides, which is then purified by the combination of silica gel, size exclusion, dual gradient, and RP-HPLC chromatography techniques. Growth kinetic studies showed that Bacillus velezensis SK produces a mixture of lipopeptides $\left(1.33 \mathrm{gL}^{-1}\right)$. The lipopeptide exhibits good $\mathrm{pH}(2-10)$ and temperature stability up to $80^{\circ} \mathrm{C}$. LC-ESI-MS analysis of partially purified lipopeptide identified variant of surfactin, further analysis of purified chromatographic fractions revealed the occurrence of most abundant $C_{15}$-surfactin homologues ( $\mathrm{m} / \mathrm{z} 1036.72 \mathrm{Da}$ ). The isolated surfactin exhibits good antimicrobial activity $(1600 \mathrm{AU} / \mathrm{ml})$ against drug-resistant food-born B. cereus and human pathogen Staphy/ococcus aureus. Hence, identified strain B. velezensis SK and its potent antibacterial surfactin lipopeptide could be used in various food and biomedical applications.
\end{abstract}

Keywords: Antibiotic-resistance, Antimicrobial peptides, B. velezensis SK, Lipopeptide, RP-HPLC, LC-ESI-MS

\section{Introduction}

Antibiotic resistance is an excellent example of microbial acclimatization towards conventional antibiotics (Wright 2007). Improper and unregulated use of antibiotics in the hospital environment, poultry industries, fish farming, and food preservation resulted in the spread and rise into antibiotic resistance phenotype (Hassan et al. 2012; Nadaf et al. 2018; Parulekar and Sonawane 2018a, b; Parulekar et al. 2019a; Wright 2007). The spread of antibiotic resistance in opportunistic pathogens associated with nosocomial infections such as Escherichia coli, Staphylococcus aureus, and Pseudomonas aeruginosa limits the therapeutic options, further resistance heighten due to pathogen in biofilm (Wright 2007). The

\footnotetext{
*Correspondence: kds_biochem@unishivaji.ac.in

${ }^{1}$ Department of Microbiology, Shivaji University, Kolhapur 416004,

Maharashtra, India

Full list of author information is available at the end of the article
}

scarcity of new antimicrobial agents for the treatment of drug-resistant microorganisms further reasoned for the spread of antibiotic resistance and emergence of multidrug-resistant strains (MDR), which has threatened human health worldwide (Alekshun and Levy 2007; Nadaf et al. 2018; Wright 2007). Thus, new effective and safe antimicrobial agents are much needed to control emerging drug-resistant microorganisms (Parulekar and Sonawane 2018a, b; Sumi et al. 2014; Wright 2007). Such health problems led down to a search for natural habitat for new potent and safe antimicrobial agents producing microorganisms from the natural environment (Chopra et al. 2014; Yang et al. 2016). The natural environment remains a promising reservoir of microorganisms, where they constantly evolve to sustain in the competitive and dynamic environment with the production of new antimicrobial agents such as antimicrobial peptides (AMPs) and lipopeptides (Alekshun and Levy 2007; Nadaf et al. 2018; Roy et al. 2015; Waghmare et al. 2019).
Springer Open

(c) The Author(s) 2022. Open Access This article is licensed under a Creative Commons Attribution 4.0 International License, which permits use, sharing, adaptation, distribution and reproduction in any medium or format, as long as you give appropriate credit to the original author(s) and the source, provide a link to the Creative Commons licence, and indicate if changes were made. The images or other third party material in this article are included in the article's Creative Commons licence, unless indicated otherwise in a credit line to the material. If material is not included in the article's Creative Commons licence and your intended use is not permitted by statutory regulation or exceeds the permitted use, you will need to obtain permission directly from the copyright holder. To view a copy of this licence, visit http://creativecommons.org/licenses/by/4.0/. 
Among the AMPs, microbial lipopeptides received considerable attention due to their structural and functional diversity with respect to size, the spectrum of antimicrobial, antifungal, and antiviral activity with low level of resistance and low toxicity (Ongena and Jacques 2008; Kulimushi et al. 2017; Malfanova et al. 2012; Ongena and Jacques 2008). Lipopeptides are group of non-ribosomally synthesized peptides (NRPs) produced by bacteria, yeast, mold, and actinomycetes (Laverty et al. 2011; Li et al. 2013; Zhao et al. 2018). In bacteria both Grampositive and Gram-negative groups of bacteria have been reported for lipopeptides production (Li et al. 2013), among them Bacillus spp are dominant (Malfanova et al. 2012; Raaijmakers et al. 2010; Zhao et al. 2016).

Lipopeptides are amphipathic peptides with hydrophilic oligopeptide (with $\mathrm{L}$ and $\mathrm{D}$ amino acids) linked to hydrophobic fatty acid chain (Zhao et al. 2016). The amino acid sequence of oligopeptide categorizes lipopeptides into iturin, fengycin, and surfactin families (Ongena and Jacques 2008). Moreover, each family of lipopeptides produced by a particular strain is varied in accordance with cultural conditions (Rangarajan and Clarke 2015). Further, each family of lipopeptides comprises its variant with subtle amino acid substitution and isoforms due to varying lengths of fatty acid (Raaijmakers et al. 2010; Zhao et al. 2017). Surfactin families (heptapeptide) of lipopeptides comprise lichenysin, pumilacidin from $B$. amyloliquefaciens, B. licheniformis, and B. pumilus (Zhao et al. 2016). Iturin (heptapeptide) group of lipopeptides consists of bacilomycins and its variants, mycosubtilysin reported from B. subtilis and B. amyloliquefaciens, while fengycin group (decapeptide) such as pilipastatin from $B$. cereus, B. thuringiensis (Ongena and Jacques 2008; Zhao et al. 2016). Another group of lipopeptides such as brevibacillin a linear cationic lipopeptide from Brevibacillus laterosporus, B. brevis reported previously (Yang et al. 2016).

Purification of each family of lipopeptide and its homologues has a great challenge, a single method of purification is insufficient to purify each family and its homologue (Varjani, and Upasani 2017). Further, its high cost of purification and low yield limits its commercialization and its various applications. However, therapeutic applications of lipopeptides need a high level of purity and it could be attained by coupled extraction and purification techniques (Rangarajan and Clarke 2015). The potency of diverse types of lipopeptides homologue against particular organisms is mainly influenced by its amino acid composition and length of fatty acid chain (Ongena and Jacques 2008; Dhanarajan et al. 2016). Among the class of lipopeptides, iturin is mainly reported for its antifungal activity against plant pathogens and fengycin for both antibacterial and antifungal activity, while surfactin shows diverse types of functions such as antibacterial, antifungal, antiviral, antitumor activity (Ongena and Jacques 2008). Although most of the literature reported lipopeptides from $B$. velezensis $s p p$. for its antifungal activity, whereas antibacterial activities especially against human pathogen relatively scare in the literature (Grady et al. 2019; Li et al. 2020a, b; Li et al. 2020a, b; Palazzini et al. 2016; Ye et al. 2018).

It is thus necessary to search for the new antimicrobial agents, hence, the present study aims to screen potent antimicrobial peptides producing strain from soil. Lipopeptides produced by $B$. velezensis SK were extracted comparatively by various extraction methods and investigated for antimicrobial efficiency and purity. Further, several purification strategies were evaluated for the effective purification of lipopeptides from $B$. velezensis SK. Further, isolated lipopeptides were identified and characterized by using analytical techniques such as TLC, FTIR, and LC-ESI-MS along with their antimicrobial potential preferably against drug-resistant bacteria along with foodborne pathogens.

\section{Materials and method Indicator microorganisms}

Indicator microorganisms used, Gram-positive organism: B. cereus NCIM 2703, B. subtilis NCIM 2635, S. aureus NCIM 2654 and Gram-negative: E. coli NCIM 2832, P. aeruginosa NCIM 5032, Proteus vulgaris NCIM 2813, Salmonella typhimurium NCIM 2501 were purchased from the National Collection of Industrial Microorganisms (NCIM), Pune and aminoglycoside resistant B. cereus ATCC 10876 from American type culture collection (Product code 0998P) Hi-Media, USA. Clinical isolate $S$. aureus and E.coli were also used for the antimicrobial activity.

\section{Screening of antimicrobial producing strain and growth media}

Total of 15 rhizospheric soil samples was collected from the Western Ghats region especially surrounding areas of Radhanagari forest, Kolhapur, and screened for antagonistic activity against selected test organisms. Briefly, $1 \mathrm{~g}$ soil sample was homogenized in normal saline by vortex mixture, $100 \mu \mathrm{l}$ aliquot from selected tenfold serial dilutions were spread plated on various media such as Nutrient agar (NA), tryptic soy agar (TSA), Muller Hinton Agar (MHA), Brain heart infusion agar (BHI), Potato dextrose agar (PDA) Hi-Media, Mumbai, India. These plates were then incubated at $25^{\circ} \mathrm{C}$ and $37^{\circ} \mathrm{C}$ temperature at $24 \mathrm{~h}$ and $48 \mathrm{~h}$. Colonies with distinct morphology were selected and transferred on nutrient agar slants; the slants were preserved at $4{ }^{\circ} \mathrm{C}$ for further analysis. The antagonistic activity of each isolate was checked by 
method described previously (Guo et al. 2012), briefly the culture from each slant spotted on Muller Hinton Agar (MHA) plate spread with indicator organism in primary screening. After incubation at $25^{\circ} \mathrm{C}$ and $37^{\circ} \mathrm{C}$ temperature for $24 \mathrm{~h}$ and $48 \mathrm{~h}$, plates were observed for the zone of inhibition around the growth of the spotted isolate. Further, isolate with potent antagonistic activity against indicator organism was checked by cross streaking method (Ganesan et al. 2017).

\section{Phenotypic, biochemical, and genotypic characterization of AMPs producer strain}

Potent antimicrobial producing isolate (B. velezensis SK) was grown on Nutrient agar (NA), colony characters noted and morphology was examined by Gram straining. Commercial HiBacillus identification kit (Himedia, Mumbai) was used for biochemical characterization. In addition, biochemical tests were performed to confirm the identity of isolated strain and compared with related strains from literature. The sugar fermentation tests such as glucose, sucrose, fructose, lactose, galactose, Mannitol, xylose, and other tests like catalase, nitrate reduction, indol, methyl red, Voges-Proskauer, citrate utilization, and hydrolysis of starch and gelatine was performed as per previous study (Li et al. 2020a, b). Further, B. velezensis SK strain was also tested for salt tolerance and antibiotic sensitivity test.

Genotypic identification of B. velezensis SK was done by using $16 \mathrm{~S}$ rRNA gene sequencing, genomic DNA was isolated from strain $B$. velezensis SK. ThermalCyclerPCRVeriti ${ }^{\circledR} 96$ well was used for the amplification of $16 \mathrm{~S}$ rRNA by using universal forward $8 \mathrm{~F}$ primer and reverse 1492R primer, amplicon of $1500 \mathrm{bp}$ purified by using $1.2 \%$ agarose gel electrophoresis and used for sequencing by Sanger method using BDTv3 .1CyclesequencingkitonABI3730xl Genetic Analyser. The resultant rRNA sequence was then used to identify closely related organisms by NCBI BLASTn in GenBank database (https://blast.ncbi.nlm.nih.gov/) and EzTaxon Database (Chun et al. 2007), briefly 16S rRNA sequence extracted in Fasta format and used for the construction of phylogenetic tree by using the Neighbor-Joining method with the help of MEGA7 (Kumar et al. 2016). The 16 s rRNA sequence was submitted to GenBank (GenBank accession number MK007327.1) and isolated strain has been preserved at Microbial Type Culture Collection, Chandigarh, India (Accession No. MTCC 25,450).

\section{Production media, inoculum preparation, and culture conditions}

Initially, the production of antimicrobial peptides from $B$. velezensis SK was evaluated in various production media such as nutrient broth (NB), tryptic soy broth (TSB)
Brain heart infusion broth (BHI), and Czapek Dox using shake flask fermentation. The inoculum was prepared by inoculating a single colony of $B$. velezensis SK strain in $50 \mathrm{ml} \mathrm{NB}$ and incubated at $37^{\circ} \mathrm{C}$ for $24 \mathrm{~h}$. Erlenmeyer flask $(250 \mathrm{ml})$ with $100 \mathrm{ml}$ working volume of respective medium were used to inoculate $3 \%$ inoculum and incubated at $37^{\circ} \mathrm{C}$ for $24 \mathrm{~h}$. Production of AMP was also evaluated at different incubation times $24 \mathrm{~h}, 48 \mathrm{~h}, 72 \mathrm{~h}$, and $96 \mathrm{~h}$ in nutrient broth. The AMPs extracted by Diaion HP-20 resin from cell-free supernatant as described further.

The media suggested by Das et al. with slight modification was used as a minimal basal medium (MBM) for the production of lipopeptides (Das et al. 2008). The MBM compose of; D-Glucose $20 \mathrm{~g} / \mathrm{l}, \mathrm{NaNO}_{3} 4 \mathrm{~g} / \mathrm{l}, \mathrm{K}_{2} \mathrm{HPO}_{4}$ $2.2 \mathrm{~g} / \mathrm{l}, \mathrm{KH}_{2} \mathrm{PO}_{4} 0.14 \mathrm{~g} / \mathrm{l}, \mathrm{NaCl} 0.01 \mathrm{~g} / \mathrm{l}, \mathrm{MgSO}_{4} \cdot 0.6 \mathrm{~g} / \mathrm{l}$, $\mathrm{CaCO}_{3} 1.0 \mathrm{~g} / \mathrm{l}, \mathrm{FeSO}_{4} 0.02 \mathrm{~g} / \mathrm{l}, \mathrm{MnSO}_{4} \cdot 4 \mathrm{H}_{2} \mathrm{O} 0.0017 \mathrm{~g} / \mathrm{l}$, $\mathrm{ZnSO}_{4} \cdot 7 \mathrm{H}_{2} \mathrm{O} 0.0016 \mathrm{~g} / \mathrm{l}(\mathrm{pH} 7.2 \pm 0.5)$. The $3 \%$ inoculum was used for the inoculation of $200 \mathrm{ml}$ production media (MBM) and incubated at $37^{\circ} \mathrm{C}$ for $48 \mathrm{~h}$ in a shaker incubator (REMI) at $120 \mathrm{rpm}$ agitation speed. All fermentations experiments were carried out in a $500 \mathrm{ml}$ Erlenmeyer baffled flask with a $200 \mathrm{ml}$ working volume.

\section{Time course growth and lipopeptide production kinetics studies of $B$. velezensis SK}

Growth kinetic studies of B. velezensis SK were performed by using MBM with composition and cultural conditions as described above; $2 \mathrm{ml}$ samples were withdrawn at a regular interval of $1 \mathrm{~h}$. This sample was then analyzed for O.D at $660 \mathrm{~nm}$ for growth, $\mathrm{pH}$, biomass estimation, residual glucose, and production of the lipopeptide. Residual glucose concentration was estimated by DNSA method, briefly cell-free supernatant mixed with DNSA reagent and boiled for 10 min O.D measured at $530 \mathrm{~nm}$, a calibration curve of glucose was prepared by using $500 \mu \mathrm{g} / \mathrm{ml}$ of glucose (Detns et al. 1959). The turbidometric method was used for the estimation of crude lipopeptide in the sample (Mukherjee et al. 2009), briefly sample was acidified to $\mathrm{pH} 2$ using $6 \mathrm{M} \mathrm{HCl}$ and turbid sample vortex and O.D was measured at $600 \mathrm{~nm}$ by using UV-Vis spectrophotometer. Calibration curve of standard surfactin (Sigma 98\% purity) was plotted against O.D at $600 \mathrm{~nm}$ vs. known concentration of surfactin in $\mu \mathrm{g} / \mathrm{ml}$.

\section{Comparison of extraction methods for efficient extraction of antimicrobial lipopeptide}

Various methods were evaluated for the extraction of bioactive peptides from cell-free supernatant. Assuming the peptide nature of the antagonistic agent, initially, ammonium sulphate at $70 \%(\mathrm{w} / \mathrm{v})$ saturation was used to precipitate all peptides and proteins, further bioactive agent was recovered by $30 \%(\mathrm{w} / \mathrm{v})$ precipitation as reported for 
purification of lipopeptides (Liu et al. 2015). An organic solvent such as chloroform $\left(\mathrm{CHCl}_{3}\right)$ and Ethyl acetate (EtoAc) in equal volume was used separately to extract an antimicrobial agent from cell-free broth. Briefly, solvent added broth was agitated for $2-3 \mathrm{~h}$ in a separating funnel and allow to separate phases (Varjani and Upasani 2017). Separated organic phase was evaporated at $40{ }^{\circ} \mathrm{C}$ and the dried residue was dissolved in methanol and checked for antagonistic activity against indicator organism. Acid precipitation using $6 \mathrm{M} \mathrm{HCl}$ was used for the partial purification of lipopeptides as reported earlier (Nanjundan et al. 2019; Varjani and Upasani 2017). Briefly cell-free supernatant acidified to final $\mathrm{pH} 2$ and kept for overnight at $4{ }^{\circ} \mathrm{C}$, precipitate was collected by centrifugation at $10,000 \times g$ at $4{ }^{\circ} \mathrm{C}$ for $15 \mathrm{~min}$ and the resultant pellet was neutralized and extracted with methanol, evaporated, and redissolved in $70 \%$ methanol (v/v) to obtain crude yellowish lipopeptide.

\section{Partial purification of lipopeptides by macroporous adsorption resin}

The method of affinity extraction using Macroporous adsorption resin (MARs) was used to isolate bioactive agents from cell-free supernatant (Dhanarajan et al. 2015), MARs such as Amberlite XAD-16 and Diaion HP-20 resins were purchased from Sigma Aldrich with physical properties as listed in Table S1, resin-treated according to manufacturer instructions. Prior to use resin was soaked in absolute methanol and then washed with water and dried at $40{ }^{\circ} \mathrm{C}$. The $2 \%$ resin was added in cell-free supernatant and kept at $37^{\circ} \mathrm{C}$ for $3 \mathrm{~h}$ for the adsorption. Further, Diaion HP-20 adsorption method was optimized for the extraction of bioactive compounds, after adsorption resin was removed and filled in chromatographic column, and washed with $500 \mathrm{ml}$ distilled water. The extraction of lipopeptides was carried out from resins by using increasing gradients of methanol as $20 \%, 40 \%, 60 \%, 80 \%$, and finally $100 \%$ (v/v) methanol, extracted lipopeptide fractions were assayed for antibacterial activity by well diffusion assay as described earlier.

\section{Purification of lipopeptide by chromatographic techniques}

\section{Purification of lipopeptide by silica gel chromatography}

The partially purified extract was loaded on silica gel (60-120 mesh) column and eluted stepwise with a linear gradient of chloroform: methanol solvent system in a ratio $\left(\mathrm{CHCl}_{3}: \mathrm{CH}_{3} \mathrm{OH}\right)$ as follows 9:1, 8:2, 7:3, 6:4, 5:5, 4:6, $3: 7,2: 8,1: 9(\mathrm{v} / \mathrm{v})$ and finally with $100 \%$ methanol (Sharma et al. 2014). Total 45 fractions of $2 \mathrm{ml}$ were collected with a constant flow rate of $1 \mathrm{ml} / \mathrm{min}$ and UV absorbance of all fractions was recorded at $280 \mathrm{~nm}$. Another elution program was also utilized using the increasing gradient of methanol: water from 3:7, 4:6, 5:5, 6:4, 7:3, 8:2, 9:1 v/v, and finally with absolute methanol (Korenblum et al. 2012), a total of 16 fractions of $5 \mathrm{ml}$ were collected. Fractions evaporated at $40{ }^{\circ} \mathrm{C}$, dissolved in methanol, and assayed for antimicrobial activity by paper disc $(30 \mu \mathrm{l})$ or agar well diffusion assay $(100 \mu \mathrm{l})$. Fractions showing antimicrobial activity pooled and analyzed by RP-HPLC.

\section{Purification of lipopeptide by Sephadex LH-20 chromatography}

Diaion HP-20 extracted lipopeptide was further purified by using Sephadex LH-20 (GE Healthcare) column (dimensions $15 \times 1.9 \mathrm{CM}$ ), prepared by Sephadex LH-20 matrix soaked in methanol overnight (Li et al. 2020a, b). The LH-20 column was equilibrated with methanol and washed several times with the same solvent. Then HP-20 bioactive extract containing lipopeptide in methanol was loaded on the column and eluted with HPLC grade methanol at a constant flow rate of $1 \mathrm{ml} / \mathrm{min}$. Total 28 fractions of $2 \mathrm{ml}$ collected, purity of separated fractions checked by TLC with solvent system ethanol: water (7:3). Spot visualized by exposing the plate to UV and also by iodine vapour. The antimicrobial activity of all fractions was checked by the paper disc method.

\section{Purification of lipopeptide by Diaion HP-20 chromatography using dual gradient technique:}

In order to separate either of the lipopeptides families produced by $B$. velezensis SK such as iturin, fengycin, and surfactin, a dual gradient of $\mathrm{pH}$ and solvent was used in this study as described by Dhanarajan et al. (2015) with slight modifications (Table S2). A glass column $(2.0 \times 50 \mathrm{~cm})$ was packed with pre-activated Diaion HP-20 resin (15 g). Then partially purified lipopeptide (5 gm) dissolved in $5 \mathrm{ml}$ distilled water was loaded on the top of the column, the column was washed with $250 \mathrm{ml}$ water and eluted stepwise by a dual gradient of $\mathrm{pH}$ and solvent acetone with $1 \mathrm{ml} / \mathrm{min}$ flow rate (Table S2). Collected fractions were neutralized, evaporated, and dissolved in methanol and analyzed by using TLC and oil displacement test as described previously. Antimicrobial activity of all fractions was performed by agar well diffusion assay, further active fractions were analyzed by RPHPLC, FTIR, and LC-ESI-MS.

\section{Reverse-phase high-performance liquid chromatography (RP-HPLC) analysis of lipopeptides}

Purification and analysis of lipopeptide homologues were carried out by using a reverse-phase high-performance liquid chromatography (RP-HPLC) system (JASCO) equipped with a quaternary pump, autosampler, and UV detector. A semi-preparative scale Hiber $\mathrm{C} 18$ column $(250 \times 4.6 \mathrm{~mm}, 5 \mu \mathrm{m})$ was used for lipopeptide 
purification as described earlier with modification (Chen et al. 2010; Sarwar et al. 2018). RP-HPLC was run in isocratic mode, $20 \mu \mathrm{l}$ Diaion HP-20 extracted sample of lipopeptide injected into column, purification of lipopeptide attempted by using mobile phase methanol/ water/trifluoroacetic in a ratio of 80:20:0.1 (v/v). The flow rate was maintained at $1 \mathrm{ml} / \mathrm{ml}$, lipopeptide peak was detected by UV detector at $210 \mathrm{~nm}$ at semi-preparative scale. The peaks correspond to standard surfactin (Sigma 98\% purity) collected, pooled, and re-injected for purity, concentrated by evaporation at $40{ }^{\circ} \mathrm{C}$, and used for further analysis.

\section{Chemical characterization of lipopeptide produced by Bacillus velezensis SK}

Thin layer chromatography (TLC) analysis of lipopeptides

Lipopeptides extracted and purified by various methods in the present study was further separated and identified by TLC by using two different solvent systems, Solvent System- I; Butanol: acetic acid: water (4:3:2) for amino acid and peptides (Seghal Kiran et al. 2010), Solvent System-II; Ethanol: water (7:3) for peptides (Balan et al. 2017). Briefly extracted lipopeptide from various preparation was spotted on silica gel plate GF 254 (Merk) and then the plate was developed by either of a solvent system described above. Then plates were visualized by various ways for the identification of nature of separated bioactive agents, such as by $0.2 \%$ ninhydrin in acetone followed by heating at $110{ }^{\circ} \mathrm{C}$ for peptides, or visualized at UV wavelength $254 \mathrm{~nm}$ or sprayed with water for lipophilic nature. Further, the lipophilic nature of the peptide was confirmed by exposing the TLC plate with iodine vapour.

\section{Bioautography of TLC separated lipopeptides}

Bioautography analysis was performed as described by Dewanjee et al. (Dewanjee et al. 2015). TLC plate was developed with solvent system-II, and dried in the oven at $40{ }^{\circ} \mathrm{C}$ for $30 \mathrm{~min}$, sterilized by exposing to UV light in laminar. The sterile TLC plate was then aseptically transferred to a sterile Petri plate and overlaid with $20 \mathrm{ml}$ soft agar (Ca-MHA) seeded with B. cereus NCIM 2703 and then allowed to solidify. The plate was incubated at $37^{\circ} \mathrm{C}$ for $24 \mathrm{~h}$ after incubation plate was observed for the spot showing a zone of inhibition. A value of the retardation factor (Rf) of the active spot was determined.

Preparative scale TLC was run in duplicate in the same condition as above, corresponding spot showing antimicrobial activity was scraped from TLC plate and eluted with $70 \%$ methanol and subjected to antimicrobial activity by disc and well diffusion assay against indicator organism at $37{ }^{\circ} \mathrm{C}$ for $24 \mathrm{~h}$ following the protocol of Clinical Laboratory Standard Institute (CLSI, 2019).
After incubation, plates were observed for the zone of inhibition.

\section{Solubility of lipopeptide produced by $B$. velezensis SK}

Solubility of purified lipopeptide was evaluated in different solvent chloroform, ethyl acetate, acetone, methanol, ethanol, and water.

\section{Effect of $\mathrm{pH}$ and Temperature on antimicrobial activity of lipopeptides}

In order to check the temperature stability of isolated surfactin lipopeptide with respect to its antimicrobial activity, $200 \mu \mathrm{l}$ of lipopeptide sample was exposed to a range of temperature $0{ }^{\circ} \mathrm{C}, 20^{\circ} \mathrm{C}, 37^{\circ} \mathrm{C}, 50{ }^{\circ} \mathrm{C}, 60{ }^{\circ} \mathrm{C}$, $70{ }^{\circ} \mathrm{C}$, and $80^{\circ} \mathrm{C}$ for $2 \mathrm{~h}$. Further, for the $\mathrm{pH}$ stability, lipopeptide was dissolved in citrate phosphate buffer of $\mathrm{pH} 2$, 4, 6, 7 and Glycine-NaOH buffer of pH 8 and 10 after $2 \mathrm{~h}$ incubation at respective buffer, mixture was then neutralized and checked for its antimicrobial activity by well diffusion assay against selected indicator microorganisms.

\section{Oil displacement test}

The biosurfactant-like character of lipopeptide produced by $B$. velezensis SK was examined by an oil displacement test as described earlier (Nanjundan et al. 2019).

\section{Fourier-transform infrared spectroscopy (FTIR) analysis of lipopeptides produced by B. velezensis SK}

Fourier transform infrared spectroscopy was used to determine the chemical nature of bioactive agent viz. lipopeptide produced by $B$. velezensis SK, by identification of the functional group. FTIR spectra of lipopeptide extracted and purified by various methods were recorded and compared with standard surfactin. Briefly, samples were mixed with vacuum-dried $\mathrm{KBr}$ and pressed into a pellet. FTIR spectra of samples were recorded in the range 4000 to $500 \mathrm{~cm}-1$ by BRUKER Alpha 100,508 FT-IR model Germany.

\section{Identification and molecular mass determination of lipopeptide by liquid chromatography mass spectroscopy LC-ESI-MS}

Active fractions from Diaion HP-20 chromatography and HPLC purified lipopeptide was first separated by capillary liquid chromatography and then analyzed by a mass spectrometer (Agilent model G6540B) equipped with ESI/ nanospray ionization quadrupole time of flight (Q-TOF) operated in positive ion mode as described earlier with minor modification (Yang et al. 2016). A sample (8 $\mu \mathrm{l})$ was dissolved in methanol and injected in capillary column (Agilent Zorbax C18 $2.1 \times 50 \mathrm{~mm} 1.8 \mu \mathrm{m}$ particle size), then separated by using mobile phase A $0.1 \%$ trifluoroacetic acid in water and mobile phase B was $0.1 \%$ 
trifluoroacetic acid in $90 \%$ acetonitrile $(\mathrm{ACN})$ at flow rate $2 \mu \mathrm{l} / \mathrm{min}$. Typically, mobile phase B increased from 2 to $40 \%$ in $60 \mathrm{~min}$ and from 40 to $90 \%$ in the next $2 \mathrm{~min}$ and then kept at $97 \%$ for the next 3 min before being decreased quickly to $3 \%$. Then, Column was equilibrated with $3 \%$ of mobile phase $\mathrm{B}$ before being the next injection.

Electrospray ionization (ESI-MS) mass spectroscopy analysis of separated peaks was performed by mass spectrometer system Agilent model G6540B) equipped with quadrupole time of flight (Q-TOF). The ESI-MS spectra were acquired in a positive ion mode with condition $3 \mathrm{kV}$ capillary voltage, $8 \mathrm{l} / \mathrm{min}$ dry gas, and $250{ }^{\circ} \mathrm{C}$ dry gas temperature. The analysis of MS spectra was programmed in a full scan of injected sample and recorded on positive ion mode within the mass range 180 to $1700 \mathrm{~m} / \mathrm{z}$.

\section{Determination of antimicrobial activity}

Antimicrobial activity of lipopeptide extracted by various methods described above was determined by various antimicrobial bioassay methods in accordance with CLSI standards (CLSI 2019; Balouiri et al. 2016); prior to use all extract was filtered sterilized by $0.22 \mu \mathrm{m}$ syringe filter (Axiva) collected in a sterile vial.

Agar well diffusion assay was mainly used for the determination of antagonistic activity during purification against selected indicator microorganisms as described in an earlier report (Balouiri et al. 2016). For this, a suspension of indicator microorganisms was prepared by adjusting turbidity to $0.5 \mathrm{McF}$ arland standard. An aliquot of $100 \mu \mathrm{l}$ suspension was spread on calcium adjusted Ca-MHA plate, $6 \mathrm{~mm}$ well was prepared and filled with $100 \mu \mathrm{l}$ antimicrobial extract $(3 \mathrm{mg} / \mathrm{ml})$. Then plates were incubated at $37^{\circ} \mathrm{C}$ for $24 \mathrm{~h}$, and observed for the zone of inhibition in diameter $(\mathrm{mm})$ around the well and measured.

The spot on lawn bioassay method was used for bioassay for the determination of arbitrary unit AU of peptide (Guo et al. 2012). Soft agar of Ca-MHA, seeded with indicator organism $(100 \mu \mathrm{l})$ overplayed onto in sterile Petri plates, and then twofold of serially diluted purified peptide $(3 \mathrm{mg} / \mathrm{ml})$ was spotted on it. After incubation at $37^{\circ} \mathrm{C}$ for $24 \mathrm{~h}$ plates were observed for the zone of inhibition in diameter $(>2 \mathrm{~mm})$ and $\mathrm{AU} / \mathrm{ml}$ calculated as follows. Antimicrobial activity of surfactin lipopeptide is expressed in arbitrary unit $\mathrm{AU} / \mathrm{ml}$; defined as reciprocal of highest dilution shows the zone of inhibition.

$$
\mathrm{AU} / \mathrm{ml}=\frac{\text { Reciprocalofhighestdilution } * 1000}{\text { Amountofdiluentspotted }}
$$

\section{Statistical analysis}

All experiments were performed in three or more replicates and results were expressed in mean \pm SD (standard deviation). Statistical significance of data was determined by applying a two-tail t-test in data analysis tool of Microsoft Excel 2013 and expressed as p-value, $\mathrm{p}<0.05$ considered as statistical significant.

\section{Results}

Screening and isolation of antimicrobial producing microorganisms

In primary screening, 150 bacterial isolates with distinct morphology were isolated as pure culture from soil samples and screened for antagonistic activity against indicator organisms (Additional file 1: Table S3). The results showed that 17 isolates out of 150 isolates have depicted antagonistic activity against indicator organisms. Moreover, isolate B4 showed broad-spectrum antimicrobial activity against seven indicator organisms including both Gram-positive as well as Gram-negative (Additional file 1: Table S3). Further, strain (B4) was identified as $B$. velezensis SK, the strain showed broad-spectrum antimicrobial activity specifically against B. cereus NCIM 2703 and S. aureus NCIM 2654 (Fig. 1a, b), which was further confirmed by agar well diffusion bioassay.

\section{Phenotypic, biochemical, and genotypic characterization of lipopeptide producer strain}

Phenotypic, morphological, and biochemical characterization was studied for selected isolate and identified as a new strain designed as $B$. velezensis SK. A new strain $B$. velezensis SK forms 2-4 mm irregular and creamy white colonies on nutrient agar (Fig. 1c, Table 1). Microscopic examination of isolate shows actively motile aerobic bacteria and by using Gram stain shows Gram-positive, rod-shaped bacteria (Table 1). Biochemical characterization of strain showed positive tests for catalase, nitrate reduction, delayed positive Voges-Proskauer, and hydrolyzed starch and gelatine (Table 1). It shows a negative reaction for indol, methyl red, glucuronidase, citrate utilization, and ONPG. The isolated strain can tolerate an $8 \% \mathrm{NaCl}$ salt concentration. The strain utilized various sugar which was demonstrated by the production of acid from D-Glucose, D-fructose, D-galactose, D-mannitol, sucrose, and negative for D-lactose. These results of carbohydrate fermentation showed that isolated strain possesses similarity with $B$. amyloliquefaciens operational group (Li et al. 2020a, b; Rabbee et al. 2019; Ruiz-García et al. 2005; Wang et al. 2020). However, the lactose negative, ONPG negative, with nitrate reduction positive make the $B$. velezensis SK strain distinct from related species as reported earlier (Additional file 1: Table S4). In addition to biochemical tests, strain B. velezensis SK showed methicillin and penicillin $G$ resistant along with moderate resistant to fusidic acid. Whereas, the strain is 

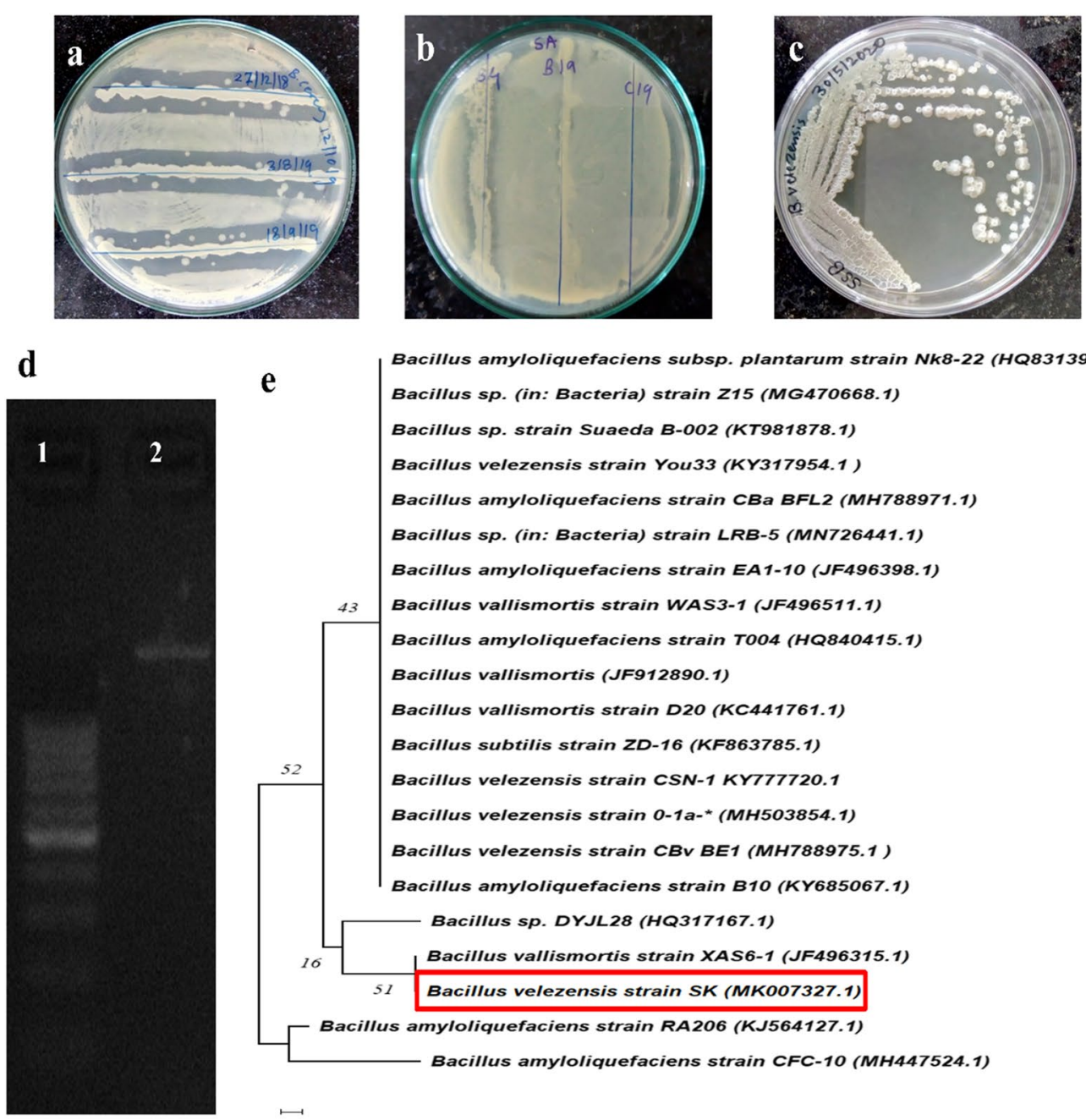

e

Bacillus amyloliquefaciens subsp. plantarum strain Nk8-22 (HQ831399.1)

Bacillus sp. (in: Bacteria) strain 215 (MG470668.1)

Bacillus sp. strain Suaeda B-002 (KT981878.1)

Bacillus velezensis strain You33 (KY317954.1)

Bacillus amyloliquefaciens strain CBa BFL2 (MH788971.1)

Bacillus sp. (in: Bacteria) strain LRB-5 (MN726441.1)

Bacillus amyloliquefaciens strain EA1-10 (JF496398.1)

Bacillus vallismortis strain WAS3-1 (JF496511.1)

Bacillus amyloliquefaciens strain TOO4 (HQ840415.1)

Bacillus vallismortis (JF912890.1)

Bacillus vallismortis strain D2O (KC441761.1)

Bacillus subtilis strain ZD-16 (KF863785.1)

Bacillus velezensis strain CSN-1 Kr777720.1

Bacillus velezensis strain 0-1a-* (MH503854.1)

Bacillus velezensis strain CBV BE1 (MH788975.1)

Bacillus amyloliquefaciens strain B1O (KY685067.1)

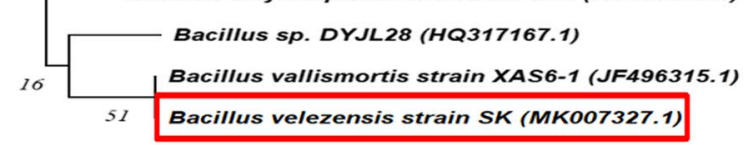

- Bacillus amyloliquefaciens strain RA206 (KJ564127.1)

Bacillus amyloliquefaciens strain CFC-10 (MH447524.1)

$\underset{0.000100}{\longmapsto}$

f
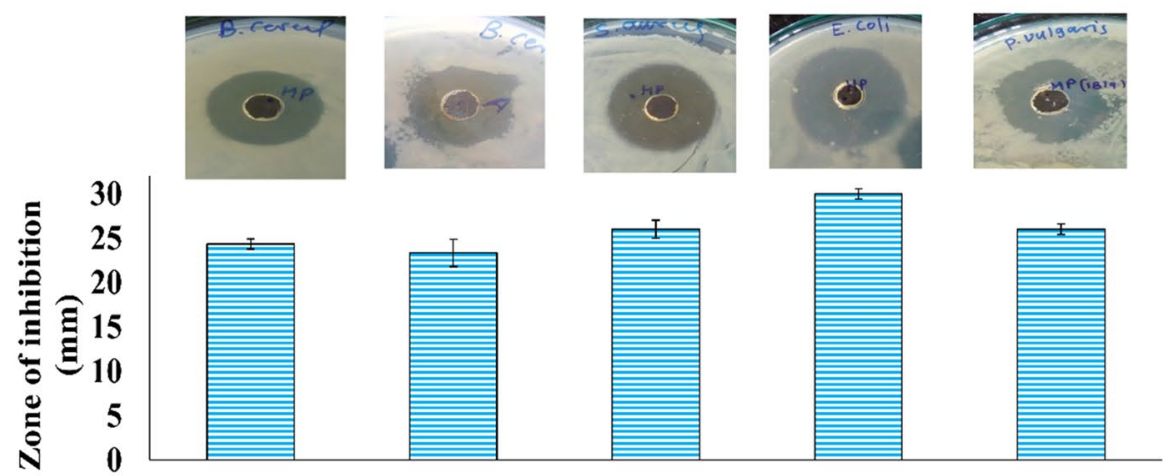

B. cereus

B. cereus $R$

S.aureus

E.coli

P. vulgaris

Microorganisms

Fig. 1 Antagonistic activity of B. velezensis SK by cross streak method against a B. cereus NCIM 2703 b Staphylococcus aureus NCIM 2654, and c Colony morphology on nutrient agar $\mathbf{d} 1500$ bp amplified 16 s rDNA. e Evolutionary relationship of B. velezensis SK based on 16 s rRNA and closely related species of Bacillus, phylogenetic tree was constructed by using Neighbour-Joining method by using MEGA7 software, bootstrap values on each branch point indicates 1000 pseudo replicates (scale represents 0.0001 nucleotide substitution). f Antimicrobial activity of partial purified (HP-20) lipopeptides by using agar well diffusion assay showing zone of inhibition (upper panel) in diameter in mm (lower panel) against Gram-positive and Gram-negative indicator bacteria including streptomycin resistant (R) 
Table 1 Morphological, physiological, and biochemical characteristics of the B. velezensis SK

\begin{tabular}{|c|c|}
\hline \multicolumn{2}{|c|}{ Microscopic examination } \\
\hline Gram's Nature & Gram-Positive \\
\hline Morphology & Rods \\
\hline Arrangements & Chains \\
\hline Motility & Actively motile \\
\hline \multicolumn{2}{|c|}{ Colony characteristics } \\
\hline Size & $2-4 \mathrm{~mm}$ \\
\hline Shape & Circular \\
\hline Surface & Rough \\
\hline Margin & Irregular \\
\hline Elevation & Raised \\
\hline Colour & White \\
\hline Opacity & Opaque \\
\hline \multicolumn{2}{|c|}{ Biochemical Characterization } \\
\hline Indol & $-V e$ \\
\hline Methyl red & $-V e$ \\
\hline Voges-Proskauer & Delayed positive \\
\hline Citrate utilization & $-V e$ \\
\hline Catalase & $+V e$ \\
\hline Glucoronidase & $-V e$ \\
\hline Nitrate reduction & $+V e$ \\
\hline ONPG & $-V e$ \\
\hline \multicolumn{2}{|l|}{ Sugar fermentation } \\
\hline Glucose & $+V e$ \\
\hline Sucrose & $+V e$ \\
\hline Fructose & $+V e$ \\
\hline Mannitol & $+V e$ \\
\hline Galactose & $+V e$ \\
\hline Lactose & $-V e$ \\
\hline Xylose & $-V e$ \\
\hline Starch hydrolysis & $+V e$ \\
\hline Gelatine hydrolysis & $+V e$ \\
\hline $\mathrm{NaCl}$ tolerance & $<8 \%$ \\
\hline
\end{tabular}

susceptible to streptomycin, chloramphenicol, tetracycline, erythromycin, and Novobiocin (Additional file 1: Figure S1a, Table S5).

Neighbor-joining phylogeny tree revealed the close relationship of $B$. velezensis SK with $B$. amyloliquefaciens operational group, with highest degree of similarity with the strains of $B$. velezensis $0-1 \mathrm{a}, B$. vallismortis XAS6-1, B. vallismortis D20, B. vallismortis WAS 3-1, B. subtilis ZD-16, and B. amyloliquefaciens EA1-10. A phylogenetic tree of $16 \mathrm{~S}$ rRNA (1458 bp) sequence of $B$. velezensis SK and its closely related species from NCBI BLASTn was constructed (Fig. 1d, e). The 16S rRNA (1458 bp) sequence of $B$. velezensis SK was also analyzed and compared with strains existing in EzTaxon
Database (Chun et al., 2007). Isolated strain B. velezensis SK forms a single clade together with closely related $B$. amyloliquefaciens, B. vallismortis, B. velezensis, and B. subtilis strain (Fig. 1e). Thus, the isolate was identified as a new bacterial strain $B$. velezensis SK based on the phenotypic, biochemical, and phylogenetic analysis.

\section{Evaluation of lipopeptide production in various media by $B$. velezensis $\mathrm{SK}$}

The new strain $B$. velezensis SK showed constitutive production of lipopeptides in nutrient broth, which can be visually monitored for production of stable foam (Additional file 1: Figure S1b). Partially purified lipopeptides by HP-20 Diaion resin, showed potent and broad-spectrum antimicrobial activity against Gram-positive and Gramnegative indicator organisms with average $\geq 24 \mathrm{~mm}$ diameter of zone of inhibition in agar well diffusion assay (Fig. 1f). Antimicrobial production from B. velezensis SK was observed after $24 \mathrm{~h}, 48 \mathrm{~h}$, and $96 \mathrm{~h}$ of incubation times in NB without significant difference (P-value $>0.05$ ) in their antimicrobial activity, suggesting $24 \mathrm{~h}$ incubation sufficient for production in NB (Additional file 1: Figure S2a).

The stain $B$. velezensis SK is capable of the production of lipopeptide in all NB, BHI, TSB, and semisynthetic Czapek Dox medium with maximum production in NB (P-value $<0.05$ ) as shown in this study (Additional file 1: Figure S2b).

\section{Time course growth and lipopeptide production kinetics studies of $B$. velezensis SK}

Growth profile of $B$. velezensis SK and its lipopeptide production kinetics against the function of time was studied in minimal basal medium (MBM) with glucose as the sole carbon source. Kim et al. (1997) reported that glucose is a superior carbon source for the lipopeptide production by $B$. subtilis $C 9$. The strain $B$. velezensis SK shows luxuriant growth in MBM after $9 \mathrm{~h}$ of lag phase and lipopeptide production started at mid $\log$ phase at $16 \mathrm{~h}$ and reach a maximum at the end of stationary phase at $36 \mathrm{~h}$ (Fig. 2a). Earlier studies showed surfactin production mainly at the late exponential phase (Ongena and Jacques 2008). Production of the lipopeptide is positively correlated with the biomass of $B$. velezensis SK, while residual glucose concentration shows a negative correlation with growth which can completely exhausted at the stationary phase at $32 \mathrm{~h}$ (Fig. 2a). One of the earlier studies with B. subtilis DSM 10 showed limiting glucose in the medium resulted in high surfactin yield, this could be due to nutritionally deprived conditions favours the lipopeptide production (Willenbacher et al. 2015).

The drop in initial $\mathrm{pH}$ value 6.4 was observed at $\log$ phase $(14 \mathrm{~h})$, which might be due to glucose utilization 

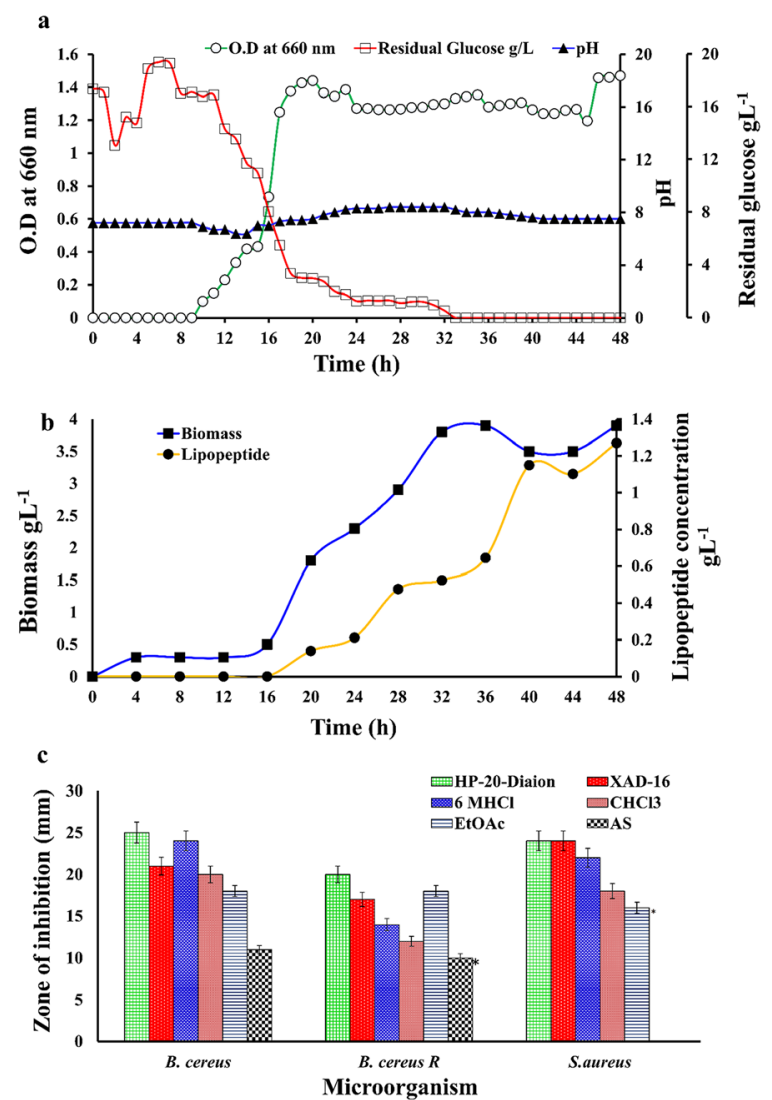

Fig. 2 a Time dependent growth curve analysis of B. velezensis SK, for growth (O.D at $660 \mathrm{~nm}$ ), residual glucose concentration and pH. b Lipopeptides production and biomass production kinetics in MBM at $37^{\circ} \mathrm{C}, 120 \mathrm{rpm}$ agitation for $48 \mathrm{~h}$. c Comparative antimicrobial activity of lipopeptides extracted by various methods from B.velezensis SK for efficient extraction against Gram-positive bacteria

and acid production (Fig. 2a). While a gradual rise in $\mathrm{pH}$ value from 6.4 at $16 \mathrm{~h}$ to 8.4 at stationary phase at $32 \mathrm{~h}$ indicates the organism might be shifted towards a new carbon source, which also indicates the progressive accumulation of lipopeptide over the $16 \mathrm{~h}$ to $32 \mathrm{~h}$ fermentation. The previous study with $B$. altitudinis MS16 also reported slight alkaline $\mathrm{pH}$ favour the lipopeptide production (Goswami and Deka 2015; Liu et al. 2019). Most of the earlier studies reported that glucose concentration at $20-40 \mathrm{gL}^{-1}$ favours lipopeptide production and was found as a best carbon ' $C$ ' source, while excess glucose concentration leads to the production of undesirable metabolites (Hmidet et al. 2017; Rangarajan and Clarke 2015). Growth and lipopeptide production studies of $B$. velezensis SK revealed that this strain can efficiently use $2 \%$ glucose and produce biomass, cell dry weight (CDW) $3.72 \pm 0.20 \mathrm{gL}^{-1}$, and produces $1.33 \pm 0.09 \mathrm{gL}^{-1}$ of lipopeptide (Fig. 2b). An earlier study by Zheng et al. (2012) has shown that the production of $1.22 \mathrm{gL}^{-1}$ surfactin from B. subtilis ATCC 21,332 in MBM media with similar composition. Our one of the experiments showed that the replacement of nitrogen source from sodium nitrate $\left(\mathrm{NaNO}_{3}\right)$ to dual nitrogen source ammonium nitrate $\left(\mathrm{NH}_{4} \mathrm{NO}_{3}\right)$ does not affect antimicrobial activity with reference to lipopeptide production. Growth curve of $B$. velezensis SK was also analyzed in nutrient broth which shows a shorter lag phase $(4 \mathrm{~h})$ as compared to lag phase in MBM (Additional file 1: Figure S3).

\section{Comparison of extraction methods for efficient extraction of antimicrobial lipopeptide}

Various methods such as ammonium sulphate, acid precipitation, solvent extraction, and various reins extraction methods were used for the extraction of antimicrobial lipopeptides, the diverse physiochemical properties of lipopeptides makes the purification process challenging (Dhanarajan et al. 2016; Goswami and Deka 2019; Lee et al. 2008; Rangarajan and Clarke 2016; Smyth et al. 2014). The results of lipopeptides precipitated by $30 \% \mathrm{w} / \mathrm{v}$ ammonium sulphate showed less antimicrobial activity against both resistant $B$. cereus ATCC 10,876 and B. cereus NCIM 2703 (Fig. 2c) as compared to antimicrobial peptide extracted by other methods in this study (Lee et al. 2008). Results of solvent such as ethyl acetate (EtoAc) and chloroform $\left(\mathrm{CHCl}_{3}\right)$ extracted lipopeptides showed no significant difference in their antimicrobial activity against the test organism, hence it is concluded that both solvents could able to extract antimicrobial peptides from broth (Fig. 2c).

However, due to the requirement of excessive solvent for extraction and limited solubility of solvent extracted lipopeptides (Rangarajan and Clarke 2016), Diaion HP-20 and XAD-16 were further used for extraction of antimicrobial lipopeptides from broth, results of both showed the significant difference in antimicrobial activity $(\geq 20 \mathrm{~mm}$ diameter zone of inhibition) against $B$. cereus NCIM 2703, streptomycin-resistant B. cereus ATCC 10,876 and $S$. aureus NCIM 2654 as compared to other methods (Fig. 2c). These results conclude that HP-20 resin with high adsorption of lipopeptides has been found better than XAD-16, which is due to the difference in their physiochemical properties (Additional file 1: Table S1) (Rangarajan and Clarke 2017). Altogether, significant differences in the antimicrobial activity of lipopeptides extracted by various methods were observed (P-value $<0.05$ ), and it was found that Diaion HP-20 resin is excellent for lipopeptide extraction as compared to others in this study (Fig. 2c). Hence, the Diaion HP-20 resin method was further optimized for effective purification by increasing the gradient of methanol, and results showed antibacterial lipopeptides efficiently extracted over $40 \%$ to $100 \%$ methanol as had antimicrobial activity 
(Additional file 1: Figure S4). All these results suggest that the lipopeptide nature of the antibacterial compound by $B$. velezensis SK which was confirmed by TLC and bioautography as described further.

Acid precipitation method for the extraction of lipopeptides from the cell-free broth was also used as per the previous report (Das et al. 2008; Ramachandran et al. 2017; Romano et al. 2013). Results showed that yellow methanolic extract of acid precipitated lipopeptides exhibit strong antimicrobial activity against $B$. cereus NCIM 2703, S. aureus NCIM 2654, and B. cereus ATCC 10,876 with $24 \mathrm{~mm}, 22 \mathrm{~mm}$, and $14 \mathrm{~mm}$ zone of inhibition respectively with no significant difference (P-value $>0.05$ ) with that of resin extracted lipopeptides (Fig. 2c). Hence, acid precipitation or resin extraction could be alternatively used for lipopeptide extraction. However, an optimized Diaion HP-20 resin method was used due to its easy operation, highest lipopeptide recovery, and purity for the lipopeptide extraction. Thus, it is clear that the combination of two or more methods could be used for the efficient purification of the antimicrobial lipopeptide.

\section{Chromatographic purification of lipopeptides produced by B. velezensis SK}

\section{Purification of lipopeptides by silica gel column} chromatography

Diaion HP-20 resin extracted lipopeptide was further purified by adsorption chromatography using silica gel (60-120 mesh) and step-wise elution by a linear gradient of chloroform and methanol $\mathrm{CHCl}_{3}: \mathrm{CH}_{3} \mathrm{OH}$, as described in the materials and methods section. The initial 19 fractions showed antimicrobial activity against B. cereus NCIM 2703 by paper disc method, which also shows maximum absorbance at $280 \mathrm{~nm}$ in UV spectroscopy highlighting the elution of lipopeptides by $\mathrm{CHCl}_{3}$ among 40 fractions (Additional file 1: Figure S5a). All of the silica column bioactive fractions were pooled together and chromatographed by TLC with ethanol: water (7:3) solvent system. The pooled bioactive fractions lack other peptide impurities as they showed the negative reaction with the ninhydrin and showed an intense yellow spot with iodine vapour indicating antimicrobial activity mainly due to lipopeptides.

Silica gel column chromatography was also performed by a linear gradient of methanol from 30 to $100 \% \mathrm{v} / \mathrm{v}$ in water based on our HP-20 extraction optimization experiment. Total 16 fractions assayed for antimicrobial activity against $B$. cereus NCIM 2703, fractions corresponding to $60 \%$ (F8) and $70 \%$ methanol (F9, F10) showed the highest antimicrobial activity against B. cereus NCIM 2703 (Additional file 1: Figure S5b). These results conclude bioactive agents were eluted better at $60-70 \%$ methanol, which agreement with our HP-20 optimization experiment, corresponding fractions were pooled and monitored for purity by TLC. The TLC results showed that single yellow spot with retardation factor (Rf) value 0.88 with iodine vapour and UV without any impurities and free amino acids with $0.2 \%$ ninhydrin analysis.

\section{Purification of lipopeptides by gel filtration column chromatography}

Fractionation of Diaion HP-20 extracted lipopeptide was also carried out by Sephadex LH-20 column with methanol as mobile phase. Total five fractions were assessed for the antimicrobial activity out of which fraction no.2 showed maximum antimicrobial activity against $B$. cereus NCIM 2703 with $24 \mathrm{~mm}$ zone of inhibition as compared to standard surfactin $(60 \mu \mathrm{g})$ which showed an $11 \mathrm{~mm}$ zone of inhibition (Additional file 1: Figure S6).

\section{Purification of lipopeptide by Diaion HP-20 chromatography using dual gradient techniques}

Dual gradient of acetone and $\mathrm{pH}$ were used to fractionate Diaion HP-20 extract as described in Additional file 1: Table S2, for the separation of families of lipopeptides (Dhanarajan et al. 2015). Antimicrobial activity of all fractions (two subfractions of F2-F6 each) from HP-20 dual gradient chromatography were checked by well diffusion assay. The results showed that fraction 2 (subfractions $2,3)$ and fraction $3(40 \%$ acetone at $\mathrm{pH} 4)$ showed lesser antimicrobial activity, which may be due to the co-elution of surfactin along with iturin (Additional file 1: Table S2, Fig. 3). Surfactin rather than iturin was mainly reported for the antibacterial activity. Decreasing polarity of mobile phase with increasing acetone content along with alteration of $\mathrm{pH}$ from 4 to 8 favours separation of iturin in initial fraction 2 (F2) from surfactin in later fractions F3, F4, F5, and F6. Although all fractions show antibacterial activity against $B$. cereus ATCC 10,876 this might be due to the presence of a small amount of surfactin. Further, strong antimicrobial activity was observed with fraction $5(80 \%$ acetone with $\mathrm{pH}$ 8) which is mainly composed of surfactin (Fig. 3). Further, the presence of iturin in fraction no. 2 and surfactin in fraction no. 5 was analyzed by RP-HPLC and finally confirmed by ESI-MS for its identification as discussed further. Hence, we hypothesized that $B$. velezensis SK produces mainly surfactin lipopeptide and a very small quantity of iturin, this might be because of cultural conditions during fermentation.

Further, all fractions checked by FTIR, oil displacement test, and TLC by iodine, the results showed the fraction F2 exhibit smooth curve similar to crude (Additional file 1: Figure S7). However, fractions F3 and F5 (Additional file 1: Table S2) show characteristic sharp peaks, 

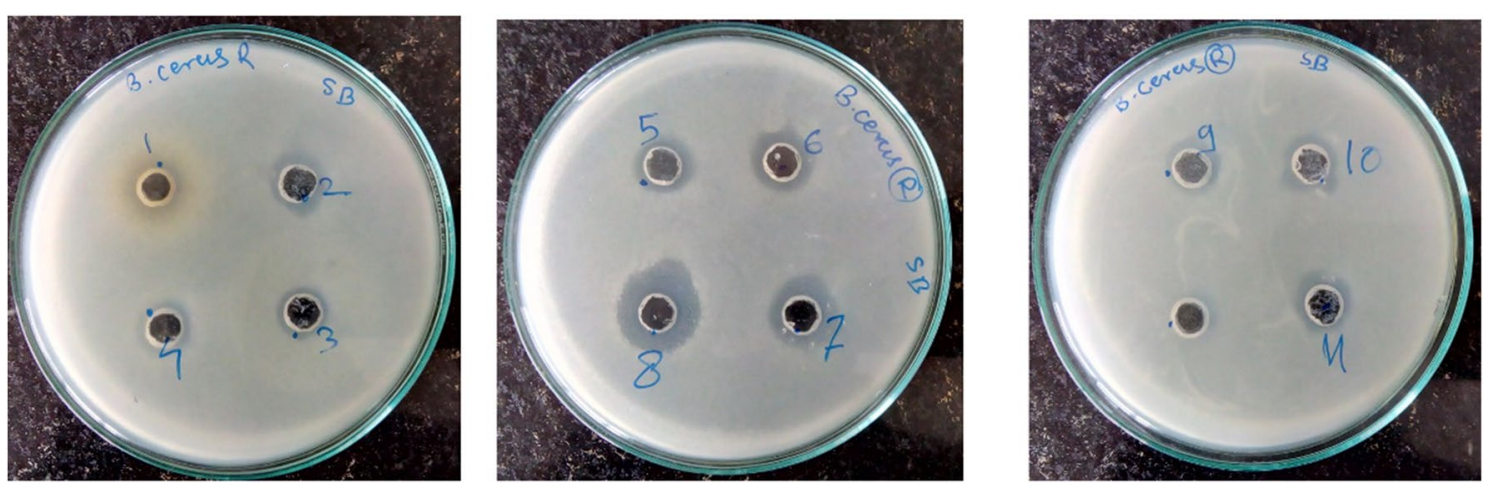

Fig. 3 Antimicrobial activity of dual gradient ( $\mathrm{pH}$ and acetone) fractions (1-11) by agar well diffusion assay against B. cereus ATCC 10,876 (6 mm well)

which is similar to standard surfactin in FTIR analysis suggest purity of isolated surfactin.

\section{Reverse phase-High performance liquid chromatography (RP-HPLC) Purification, analysis of lipopeptides}

The lipopeptides extracted by various methods and purified by chromatographic techniques exhibiting antimicrobial activity were further subjected to RP-HPLC analysis and compare with standard surfactin.

Chromatogram of chloroform/methanol extract showed four distinct peaks at a retention time (Rt) of $2.91 \mathrm{~min}, 4.02 \mathrm{~min}, 5.47 \mathrm{~min}$, and $6.8 \mathrm{~min}$ which corresponds to standard surfactin with its homologues at the retention time of $2.61 \mathrm{~min}, 3.0 \mathrm{~min}$, and $4.20 \mathrm{~min}$ (Fig. 4a and b). Additional peaks of chloroform extracted lipopeptides as compared to standard surfactin signified the presence of a newer surfactin isoform (Fig. 4b). Similarly, RP-HPLC analysis of Diaion HP-20 extracted lipopeptide showed two peaks at the retention time of $2.65 \mathrm{~min}$ (major) and $3.98 \mathrm{~min}$ (Additional file 1: Figure S8). A similar type of peaks has been observed for lipopeptide extracted by ethyl acetate, XAD-16 and purified by silica gel and Sephadex LH-20 column, which showed a major peak at Rt of $2.83 \mathrm{~min}$, $2.74 \mathrm{~min}, 2.91 \mathrm{~min}$, and $2.69 \mathrm{~min}$ respectively with other minor peaks (Additional file 1: Figure S8). The slight deviation in retention time of lipopeptides peaks from various extracts might be due to the presence of surfactin isoforms. These observations and peak analysis of extracted and column purified lipopeptides by RP-HPLC highlights the abundance of surfactin and its homologues when compare to standard surfactin which revealed that $B$. velezensis SK produces surfactin and its homologues. The coupled LH-20 and RP-HPLC purified surfactin lipopeptide showed antimicrobial activity with $13 \mathrm{~mm}$ zone of inhibition against $B$. cereus NCIM 2703 by well diffusion assay (Additional file 1: Figure S8e, inset), Iturin produced by B. velezensis SK could not be able to detect by RP-HPLC due to its less amount as compared to surfactin and its homologues.

\section{Physiochemical properties and chemical characterization of lipopeptide produced by $B$. velezensis SK}

Thin layer chromatography of lipopeptides

The TLC analysis of lipopeptide extracted and column purified by various methods was done by using two solvent systems as described previously (Jha et al. 2016; Seghal Kiran et al. 2010). The TLC analysis results of chloroform/methanol extracted and HP-20 extracted lipopeptides from NB and MBM by chromatogram developed with solvent system-I, showed one yellow spot which is negative for ninhydrin with retardation factor (Rf) value 0.83 (Fig. 5a). Similarly, three spots were observed for iodine vapour and visible under UV (254) in TLC developed by solvent system-II with Rf value $0.89,0.84$, and 0.78 respectively for lipopeptide extracted by HP-20 from NB and MBM (Fig. 5b and c). The spot with Rf value 0.83 in solvent system-I and 0.89 in solvent system-II is considered as of the same lipopeptide which becomes white when sprayed with water. TLC analysis with solvent system II (Ethanol water 7:3) showed better resolution than system-I, hence further TLC analysis carry forward with solvent system-II for monitoring impurities in post chromatographic fractions. In conclusion, TLC analysis results showed more impurities in HP-20 extracted lipopeptide from NB as compared to chloroform, acid precipitated methanolic extract and from mineral base media, when sprayed with $0.2 \%$ Ninhydrin. 

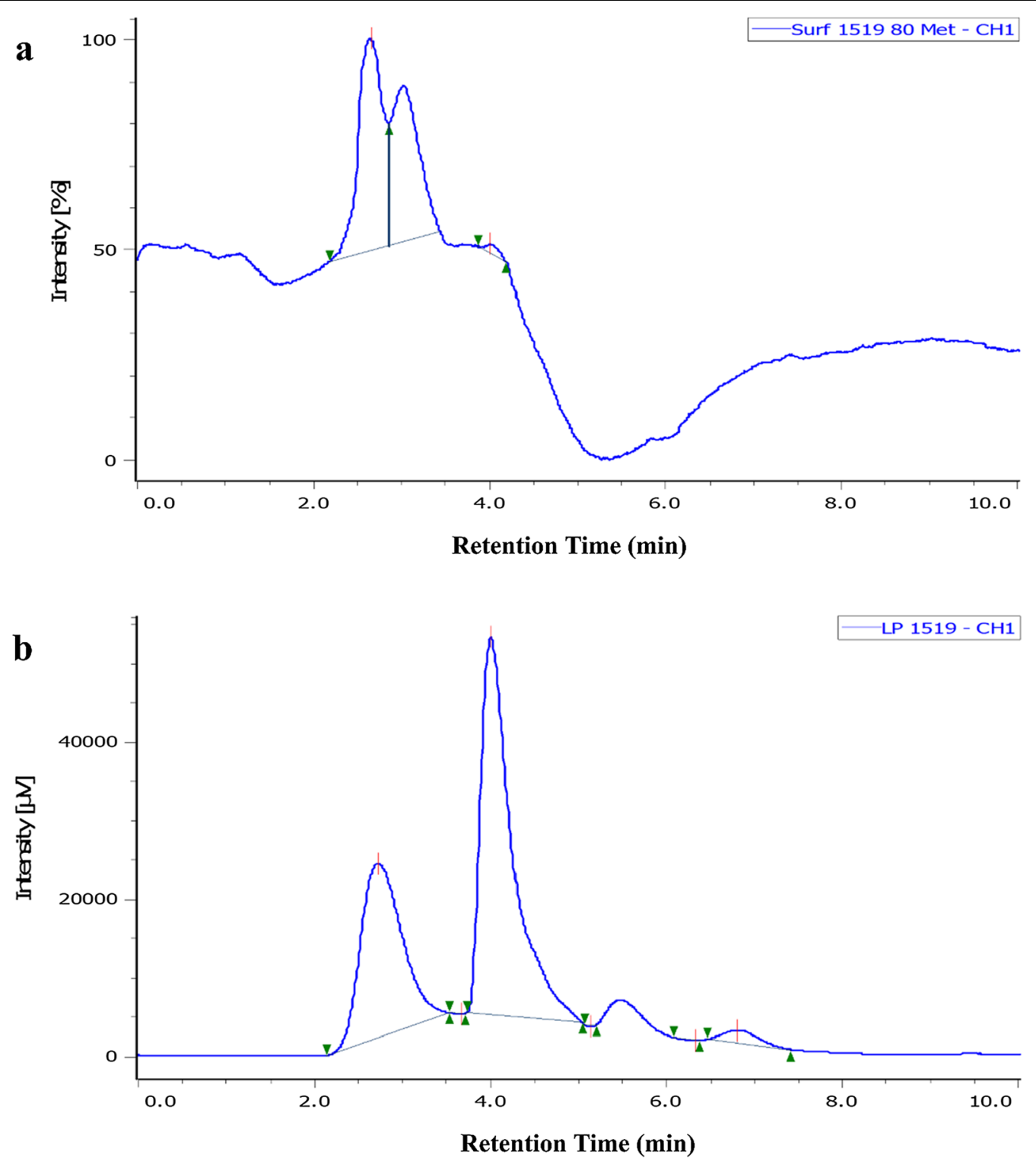

Fig. 4 Reverse-phase HPLC purification of lipopeptides produced by B. velezensis SK Chromatogram of a Standard surfactin, $\mathbf{b}$ Chloroform extracted lipopeptides using mobile phase $80 \%$ methanol in water over 30 min

\section{Bioautography of TLC separated lipopeptides}

In order to identify and confirm the bioactivity of TLC separated lipopeptides, TLC plate developed with solvent system-II, and were analyzed by bioautography using B. cereus NCIM 2703 as an indicator organism. Bioautography results showed only a spot with $\mathrm{Rf}$ value of 0.89 had the zone of inhibition against B. cereus NCIM 2703 (Fig. 5d). In order to confirm bioactivity of iodine positive spots, respective spots scraped from the TLC plate eluted with methanol and assessed for antimicrobial activity by well diffusion, the spot with Rf value 0.89 showed a $1.5 \mathrm{~mm}$ zone of inhibition against B. cereus NCIM 2703 (Fig. 5e and f) while other two spot lack antagonistic activity.

The cyclic and peptide nature of bioactive agent viz. lipopeptides was further confirmed by hydrolysis of TLC eluted peptide by $6 \mathrm{M} \mathrm{HCL}$ at $121{ }^{\circ} \mathrm{C}$ for $4 \mathrm{~h}$. The results showed before hydrolysis no purple colour was observed with $0.2 \%$ ninhydrin (Fig. $5 \mathrm{~g}$ Lane No. 1) while acid hydrolyzed fraction shows the development of purple colour confirms the cyclic nature of lipopeptide (Fig. 5g Lane No. 2). Developed spots corresponding to standard amino acid leucine and valine (Fig. $5 \mathrm{~g}$ 

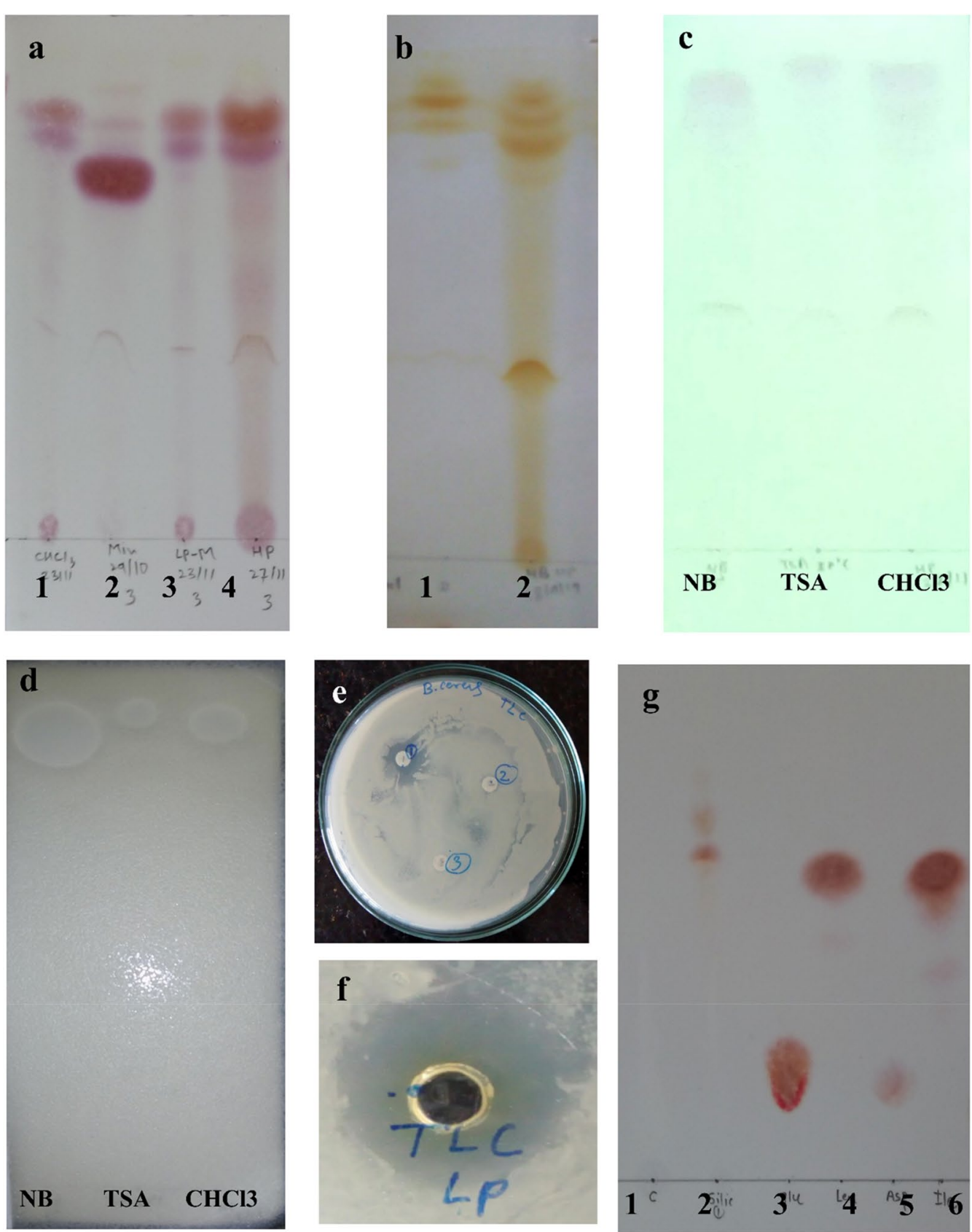

Fig. 5 Thin layer chromatography (TLC) of partial purified lipopeptides from B. velezensis SK using a Solvent system-I and visualized with $0.2 \%$ ninhydrin, Lane 1, 2, 3, and 4 correspond to lipopeptide extracted with chloroform, lipopeptides produced in MBM, acid precipitated and methanol extracted lipopeptides and Diaion HP-20 lipopeptides respectively. b Solvent System-II and visualized by iodine vapour, TLC analysis of lipopeptide extracted by HP-20 lane 1 (MBM) and lane 2 (NB). c TLC plates of Diaion HP-20 extracted lipopeptide from NB visualized by UV 254 nm lane1, TSA lane 2, and Chloroform extracted lipopeptides lane 3 using solvent system-II. $\mathbf{d}$ In-situ antimicrobial activity of separated lipopeptides against $B$. cereus NCIM 2703 by using autobiography technique, and e Antimicrobial activity of TLC separated (upper spot) and eluted spots (disk 1) against $B$. cereus NCIM 2703 by paper disk assay. f Antimicrobial activity of TLC eluted (spot 1) bioactive spot by agar well diffusion assay. $\mathbf{g}$ TLC analysis of acid hydrolyzed purified lipopeptide fraction (Lane 2) and intact lipopeptide (Lane 1) as compared to amino acids Glutamate, Leucine, Aspartate and isoleucine lane 3, 4, 5, and 6 respectively after visualization by ninhydrin using solvent system-I 
Lane No. 3, 4, 5, 6), which highlights cyclic lipopeptide might contain leucine and valine.

\section{Effect of temperature and $\mathrm{pH}$ on antibacterial lipopeptide and its solubility}

Stability of extracted lipopeptide has been evaluated at various temperatures and $\mathrm{pH}$ with respect to its antagonistic activity, extracted lipopeptide showed thermostability over wide range of temperatures $0-80{ }^{\circ} \mathrm{C}$. Specifically, lipopeptide exposed at temperatures $0{ }^{\circ} \mathrm{C}, 20$ ${ }^{\circ} \mathrm{C}$, and $37{ }^{\circ} \mathrm{C}$ retained maximum antimicrobial activity with a $24 \mathrm{~mm}$ zone of inhibition against $B$. cereus NCIM 2703 and S. aureus NCIM 2654 (Fig. 6a). Lipopeptides produced by $B$. velezensis SK showed $\mathrm{pH}$ stability over the range of 2 to 10 , as the antimicrobial activity retained against B. cereus NCIM 2703 and E. coli NCIM 2832 (Fig. 6b). These results suggest that lipopeptide produced by $B$. velezensis SK exhibits good temperature $\left(0-80{ }^{\circ} \mathrm{C}\right)$ and $\mathrm{pH}(2-10)$ stability and become potential applications in the biomedical and food industry. HPLC purified lipopeptide is soluble in $70 \%$ methanol, ethanol, and acetone, whereas partially soluble in distilled water and insoluble in chloroform and ethyl acetate.

\section{Fourier-transform infrared spectroscopy (FTIR) analysis of lipopeptides produced by $B$. velezensis SK}

Chemical nature of bioactive compound i.e. lipopeptide produced by $B$. velezensis SK has been determined by the identification of functional groups present in the compound. FTIR spectra (Fig. 6c) exhibit strong absorption over 3240 to $3500 \mathrm{~cm}^{-1}$, with maxima at $3317 \mathrm{~cm}^{-1}$ which is due to $-\mathrm{N}-\mathrm{H}, \mathrm{C}-\mathrm{H}$, and $-\mathrm{OH}$ stretching, indicate the presence of carbon containing compound and with an amino group, absorption at this range also implies presence of intermolecular hydrogen bonds (Das et al. 2008). Presence of a sharp peak at $1647 \mathrm{~cm}^{-1}$ is indicative of the presence of amide group $-\mathrm{C}-\mathrm{N}$ and carbonyl group stretching vibrations of protein and peptide (Jha et al. 2016; Sharma et al. 2018). The sharp absorption peak at $2825 \mathrm{~cm}^{-1}$ and $2939 \mathrm{~cm}^{-1}$ indicates the presence of a long aliphatic chain congaing $-\mathrm{CH},-\mathrm{CH}_{2}$, $-\mathrm{CH}_{3}$ such as the fatty acid chain of the lipopeptide. In addition, absorption peak at $1419 \mathrm{~cm}^{-1}$ and $1450 \mathrm{~cm}^{-1}$ might correspond to $\mathrm{C}-\mathrm{H}$ alkyl bond vibration of aliphatic amino acids such as Leu, Ile, and absorption at $1112 \mathrm{~cm}^{-1}$ is due to vibration ester bond (Das et al. 2008; Kumar et al. 2009). Obtained spectra of purified lipopeptide from B. velezensis SK showed a similar type of bond stretching and vibration as standard surfactin (Sigma 98\%). FTIR spectra of lipopeptides from B. velezensis SK also showed similarities with previously reported lipopeptides produced by $B$. amyloliquefaciens SAS-1 and B. subtilis BR-15 (Sharma et al. 2018). Hence, obtained

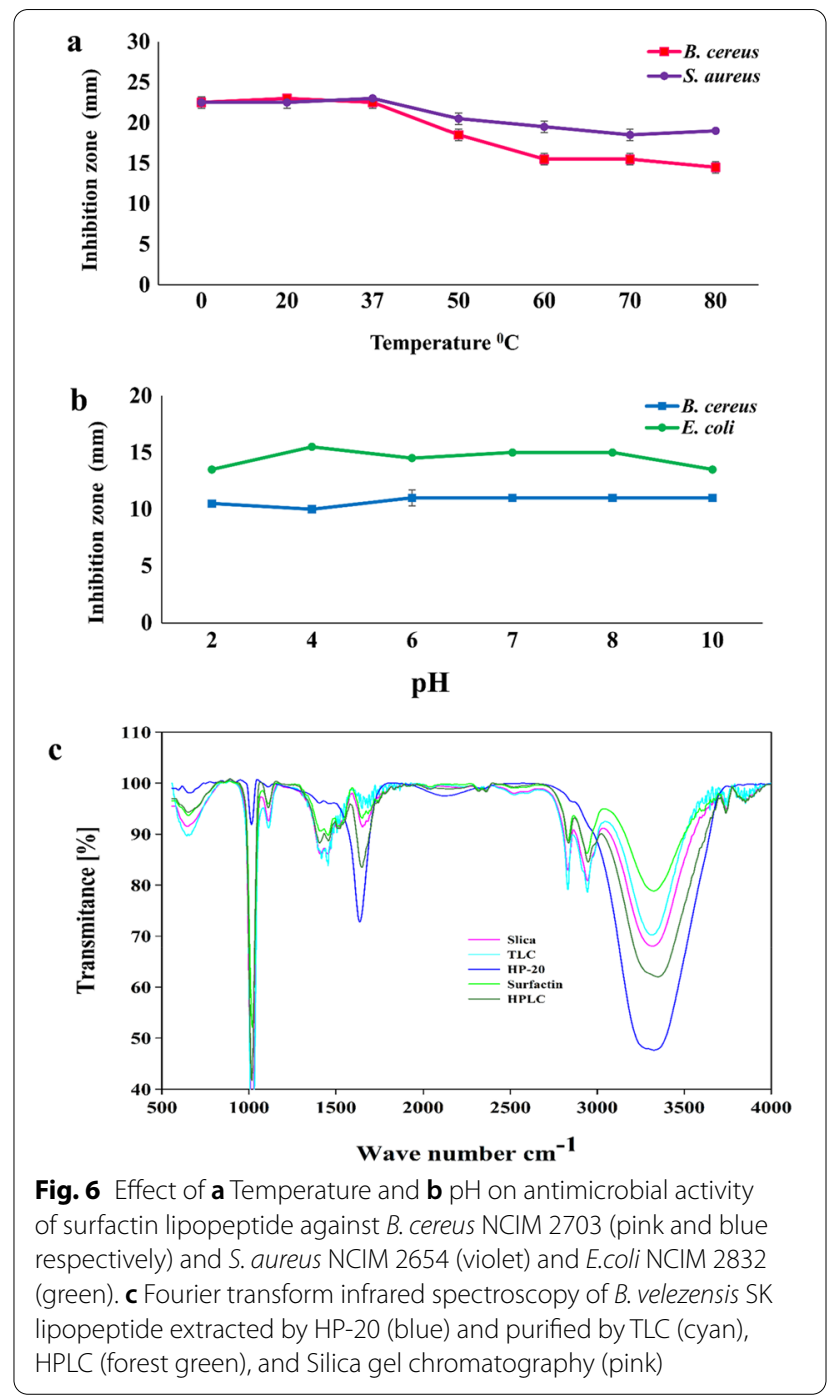

results conclude that the antimicrobial peptide produced by $B$. velezensis SK is a cyclic lipopeptide containing a fatty acid chain and peptide backbone.

Lipopeptide extracted by Diaion HP-20 and $\mathrm{CHCl}_{3}$ shows smooth peaks, whereas TLC eluted, Silica gel fraction, and HPLC purified lipopeptides showed sharp peaks exactly similar to spectrum with standard surfactin (Fig. 6c and Additional file 1: Figure S7). FTIR analysis of lipopeptide extracted from cell-free culture media by methods described above also revealed the quality and purity of lipopeptides (surfactin).

\section{Identification and mass spectroscopic analysis} of lipopeptides produced by B. velezensis SK (LC-ESI-MS) Lipopeptide produced by $B$. velezensis SK purified by various methods further identified by LC-ESI-MS. LCESI-MS analysis of the partially purified HP-20 extract showed two clusters of peaks (Additional file 1: Figure 
S9a), ESI-MS analysis of peak at retention time (Rt) 46 to 56 min reveals a group of protonated molecular ion peak $[\mathrm{M}+\mathrm{H}]^{+}$of $\mathrm{m} / \mathrm{z}$ ratio $1043.58,1057.59$, and 1071.61 indicating the presence of iturin homologues $\left(\mathrm{C}_{14-16}\right)$, each of differs in the mass of 14 Da relative to $-\mathrm{CH}_{2}-$, which also influence its retention time with a marginal difference (Additional file 1: Figure S10 a, b and c; Table 2). Second cluster of peaks observed at the range of retention time 62 to 64 min in LC (Additional file 1: Figure S9a), further ESI-MS analysis of these cluster of peaks revealed protonated molecular ion peaks $[\mathrm{M}+\mathrm{H}]^{+}$of $\mathrm{m} / \mathrm{z}$ ratio 994.67, 1008.69, 1022.70, and 1036.72 corresponds to four surfactin homologues $\mathrm{C}_{12}$-surfactin, $\mathrm{C}_{13}$-surfactin, $\mathrm{C}_{14}$-surfactin, and $\mathrm{C}_{15}$-surfactin respectively (Additional file 1: Figure S10d). Molecular ion peaks of lipopeptides obtained from B. velezensis SK in this study compare with average molecular ion mass of iturin and surfactin from literature (Dhanarajan et al. 2016; Goswami and Deka 2019; Souza et al. 2018; De Faria et al. 2011; Dang et al. 2019; Liu et al. 2020; Chen et al. 2020). LC-ESI-MS data of HP-20 extract suggest the B. velezensis SK mainly produce surfactin homologues with $76.75 \%$ relative abundance as compared to iturin $23.24 \%$ relative abundance (Table 2) in partially purified HP-20 extract. Further, within each family $\mathrm{C}_{13}$-Surfactin and $\mathrm{C}_{14}$-Iturin are found to be most abundant homologues (Table 2). Relative abundance is calculated by summing the major peak of all homologues ( 46 to 56 and 62 to $64 \mathrm{Rt}$ ) area and expressed as each family of lipopeptides as a percent value.

LC-ESI-MS analysis of HP-20 dual gradient fractions (F2 and F5) showed separation of iturin in fraction 2 (25\% acetone) which shows two peaks (Additional file 1: Figure $\mathrm{S} 9 \mathrm{~b}$ ), one around retention time of 45-50 and other at range of 62 to 64 , which is similar to mass and retention time observed in LC-MS analysis of partially purified HP-20 extract. The ESI-MS analysis confirms the presence of negligible amount of iturin (relative abundance $0.91 \%)$ with molecular ion peaks $[\mathrm{M}+\mathrm{H}]^{+} 1043.58$ and 1057.59 (Additional file 1: Figure S11a and b) and most

Table 2 LC-ESI-MS identification of surfactin and iturin type of homologues produced by B. velezensis SK, and comparison of their Molecular weight and peptide sequence reported in literature (Dhanarajan et al. 2016; Goswami and Deka 2019; Souza et al. 2018; De Faria et al. 2011; Dang et al. 2019; Liu et al. 2020; Chen et al. 2020)

\begin{tabular}{|c|c|c|c|c|c|}
\hline $\mathrm{RT}$ (min) & $\begin{array}{l}\text { Observed MW } \\
{[M+H]^{+}(\mathrm{m} / \mathrm{z})}\end{array}$ & $\begin{array}{l}\text { Average MW } \\
\text { reported }\end{array}$ & Identified lipopeptide & $\begin{array}{l}\text { Relative } \% \text { of } \\
\text { lipopeptide family }\end{array}$ & $\begin{array}{l}\text { Amino acid sequence } \\
\text { (Obtained from literature) }\end{array}$ \\
\hline \multicolumn{6}{|c|}{ HP-20 Extract } \\
\hline \multicolumn{6}{|l|}{ Peak first } \\
\hline 45.89 & 1043.58 & 1042.7 & $\mathrm{C}_{14^{- \text {Iturin }}}$ & 11.37 & Cyclic (FA-N-Y-N-Q-P-N-S) \\
\hline 49.97 & 1057.59 & 1057.6 & $\mathrm{C}_{15}$ - Iturin & 5.00 & Cyclic (FA-N-Y-N-Q-P-N-S) \\
\hline 55.33 & 1071.61 & 1071.7 & $C_{16-\text { Iturin }}$ & 6.86 & Cyclic (FA-N-Y-N-Q-P-N-S) \\
\hline \multicolumn{6}{|c|}{ Peak second } \\
\hline \multirow[t]{4}{*}{63.52} & 994.67 & 994.21 & $\mathrm{C}_{12}$-Surfactin & 17.49 & Cyclic (FA-E-L/I-L/I-V- L/I- D-L) \\
\hline & 1008.69 & 1008.87 & $\mathrm{C}_{13}$-Surfactin & 27.73 & Cyclic (FA-E-L/I-L/I-V- L/I -D-L) \\
\hline & 1022.70 & 1023.18 & $\mathrm{C}_{14}$-Surfactin & 19.11 & Cyclic (FA-E-L/I-L/I-V-V-D-L) \\
\hline & 1036.72 & 1036.78 & $\mathrm{C}_{15}$ Surfactin & 12.40 & Cyclic (FA-E-L/I-L/I-V- L/I -D-L) \\
\hline \multicolumn{6}{|c|}{ Fraction 2 (40\% Acetone $\mathrm{pH} 4$ ) } \\
\hline \multicolumn{6}{|l|}{ Peak first } \\
\hline 45.88 & 1043.58 & 1042.7 & $C_{14}$-Iturin & 0.71 & Cyclic (FA-N-Y-N-Q-P-N-S) \\
\hline 50.48 & 1057.59 & 1057.6 & $C_{15}$-lturin & 0.20 & Cyclic (FA-N-Y-N-Q-P-N-S) \\
\hline \multicolumn{6}{|c|}{ Peak second } \\
\hline 62.42 & 1036.72 & & $\mathrm{C}_{15}$-Surfactin & 44.34 & Cyclic (FA-E-L/I-L/I-V-D -L/I-L) \\
\hline \multirow[t]{5}{*}{63.54} & 994.67 & 994.21 & $\mathrm{C}_{12}$-Surfactin & 54.74 & Cyclic (FA-E-L/I-L/I-V-D-L/I-L) \\
\hline & 1008.69 & 1008.87 & $\mathrm{C}_{13}$-Surfactin & & Cyclic (FA-E-L/I-L/I-V-D-L/I-L) \\
\hline & 1022.70 & 1023.18 & $\mathrm{C}_{14}$-Surfactin & & Cyclic (FA-E-L/I-L/I-V-D-L/I-L) \\
\hline & 1036.72 & 1036.78 & $C_{15}$-Surfactin & & Cyclic (FA-E-L/I-L/I-V-D-L/I-L) \\
\hline & 1050.73 & 1050.92 & $\mathrm{C}_{16}$-Surfactin & & Cyclic (FA-E-L/I-L/I-V-D-L/I-L) \\
\hline \multicolumn{6}{|c|}{ Fraction 5 (80\% Acetone pH 8) } \\
\hline 62.20 & 994.67 & 994.21 & $\mathrm{C}_{12}$-Surfactin & 24.17 & Cyclic (FA-E-L/I-L/I-V-D-L/I-L) \\
\hline \multirow[t]{2}{*}{63.38} & 1022.70 & 1023.18 & $\mathrm{C}_{14}$-Surfactin & 32.18 & Cyclic (FA-E-L/I-L/I-V-D-L/I-L) \\
\hline & 1036.72 & 1036.78 & $\mathrm{C}_{15}$-Surfactin & 43.64 & Cyclic (FA-E-L/I-L/I-V-D-L/I-L) \\
\hline
\end{tabular}


abundant surfactin $(99.08 \%)$ with its homologues having $\mathrm{m} / \mathrm{z}$ ratio $[\mathrm{M}+\mathrm{H}]^{+}$994.67, 1008.69, 1022.70, 1036.72 (most abundant 44.34\%) and 1050.73 (Additional file 1: Figure S11c, d). In detail, Rt of peaks detected in all fractions along with their relative abundance and assignment of lipopeptides homologues were shown in Table 2.

LC-ESI-MS analysis of fraction 5 (F5) showed a major peak at $63 \mathrm{~min}$ (Figure S9c) with molecular ion peak of $\mathrm{m} / \mathrm{z} 1036.72$ (43.64\% relative abundant) correspond to most abundant homologues $\mathrm{C}_{15}$-surfactin (Fig. 7a, b, and c). A similar type of scenario was observed with HPLC purified surfactin lipopeptides with $80 \%$ methanol. Overall, LC-ESI-MS analysis of HP-20 extract and dual gradient chromatography fractions (F2 and F5) confirmed the separation of iturin in fraction 2 from fraction 5 (consist most abundant surfactin isoforms), hence we conclude that the B. velezensis SK mainly produce surfactin type of lipopeptide.

\section{Antimicrobial activity of lipopeptide}

Indicator organisms for antimicrobial activity include streptomycin-resistant $B$. cereus ATCC 10,876 and opportunistic pathogens such as S. aureus NCIM 2654 and methicillin-resistant S. aureus (MRSA). Surfactin lipopeptide showed the highest antimicrobial activity by spot on lawn method against non-resistant $B$. cereus NCIM 2703 with 32,000 AU/ml and six months stored extract (aliquot) with $16,000 \mathrm{AU} / \mathrm{ml}$ reflecting its stability during storage (Table 3). Similarly, both partially purified surfactin and surfactin stored at $4{ }^{\circ} \mathrm{C}$ showed a similar degree of inhibitory activity at $16,000 \mathrm{AU} / \mathrm{ml}$ against streptomycin-resistant B. cereus ATCC 10,876 and S. aureus NCIM 2654, while stored aliquot with lesser activity $400 \mathrm{AU} / \mathrm{ml}$. The antagonistic activity was also tested against methicillin-resistant $S$. aureus; results showed inhibitory activity with $800 \mathrm{AU} / \mathrm{ml}$ slightly more as compared to stored lipopeptide $400 \mathrm{AU} / \mathrm{ml}$. Our results including agar well diffusion assay showed the potent and broad-spectrum antimicrobial activity against Gram-positive including drug-resistant and Gramnegative organisms. Hence, partially purified lipopeptide could be useful to control drug-resistant organisms present in the hospital environment as a disinfectant, as stated earlier study by Singh et al. which demonstrated the disinfectant-like activity of lipopeptides produced by B. tequilensis strain SDS21 (Singh and Sharma 2020).

\section{Discussion}

AMPs could be an alternatives for the conventional antibiotics to which microorganisms especially opportunistic pathogens developed resistance and thus essential to control (Alekshun et al. 2007; Hassan et al. 2007; Nadaf et al. 2018). To overcome the resistance problem, present study was aimed to search for potent AMPs producing microorganisms. In primary screening, we isolated and identified a new potent antimicrobial lipopeptide producing strain B. velezensis SK by genotypic, morphologically characterization, as it displays broad-spectrum antimicrobial activity against both Gram-positive and Gram-negative bacteria including drug-resistant opportunistic pathogens.

Further, lipopeptide production was evaluated in various media and results showed isolated $B$. velezensis SK could able to produce lipopeptides in all media tested including MBM. Earlier, B. velezensis and related species have been shown to produce lipopeptides $(0.818$ $\mathrm{gL}^{-1}$ ) from different agro-industrial wastes and office waste such as paper hydrolyzed by $B$. velezensis ASN1 which can be used in the production medium to lower the cost of production (Jha et al., 2016; Nair et al. 2020). Time course and lipopeptide production kinetic experiments with $\mathrm{MBM}$ revealed that $\mathrm{CuSO}_{4}$ completely inhibits the production of lipopeptide by $B$. velezensis SK, while the presence of $\mathrm{Zn}^{2+}$ is unaffected. Earlier studies highlighted that these trace elements along with $\mathrm{Co}^{2+}$, and $\mathrm{Ni}^{2+}$ inhibit the growth and lipopeptide production of B. subtilis (Rangarajan and Clarke 2015). The ESI-MS analysis of the crude extract and purified fractions receives attention as it highlights the presence of surfactin and its isoforms as a major constituent (Table 2), although several earlier studies report the production of three types of lipopeptides from Bacillus Spp. (Iturin, fengycin, and surfactin) with similar cultural conditions within 24-72 h and mainly reported for antifungal activity (Chen et al. 2020; Li et al. 2020a, b; Liu et al. 2020; Sarwar et al. 2018), interestingly $B$. velezensis SK with culture conditions $\left(37^{\circ} \mathrm{C}, 120 \mathrm{rpm}\right.$ in $48 \mathrm{~h}$ ) in this study mainly found for antibacterial surfactin production. However, earlier studies based on genome analysis have been reported for several antagonistic agents from Bacillus velezensis and Bacillus Spp. (Grady et al. 2019; Li et al. 2020a, b; Li et al. 2020a, b; Palazzini et al. 2016; Wu et al. 2016), hence presented culture conditions and subsequent extraction of antimicrobial with HP-20 could be useful for selective surfactin production and extraction, purification.

Most previous studies reported acid precipitation for lipopeptides isolation from a variety of bacterial strains (De Faria et al. 2011; Das et al. 2008; Rangarajan and Clarke 2016; Sarwar et al. 2018; Singh and Sharma 2020). Present study also focuses on comparative lipopeptide extraction methods for an easy and convenient extraction process, which found that the lipopeptides extracted better with HP-20 Diaion resin from culture medium with remarkable antimicrobial activity against a broad range of bacteria among other extraction methods. 


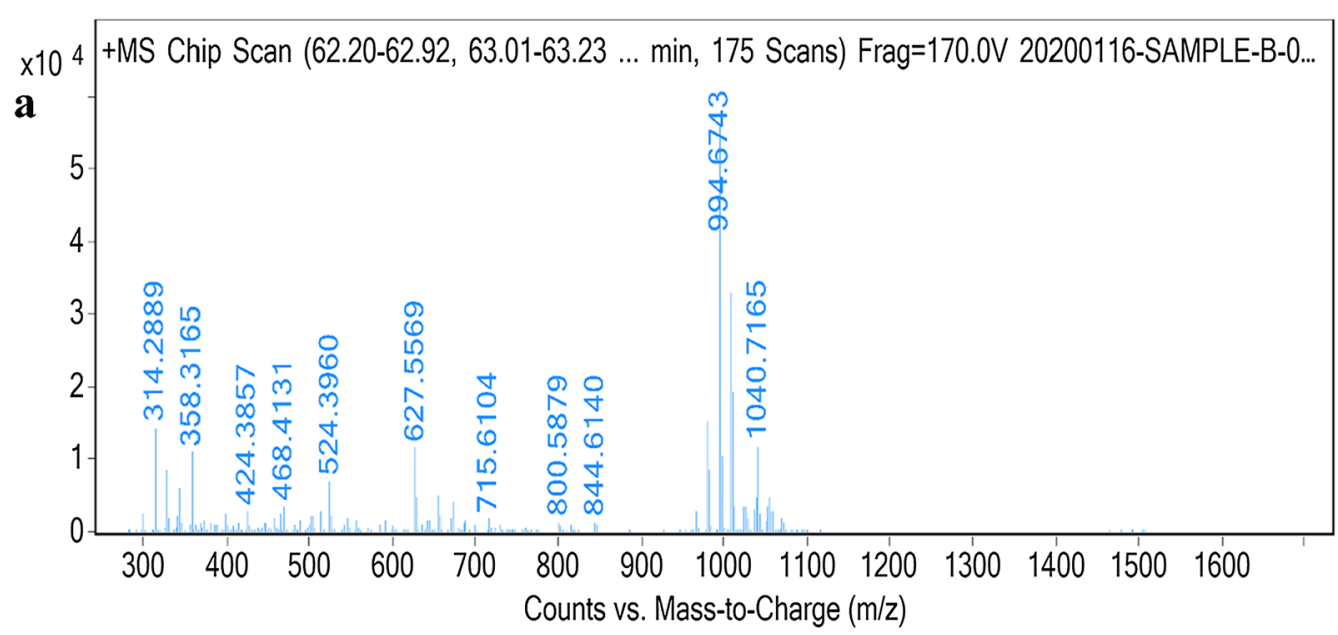

b
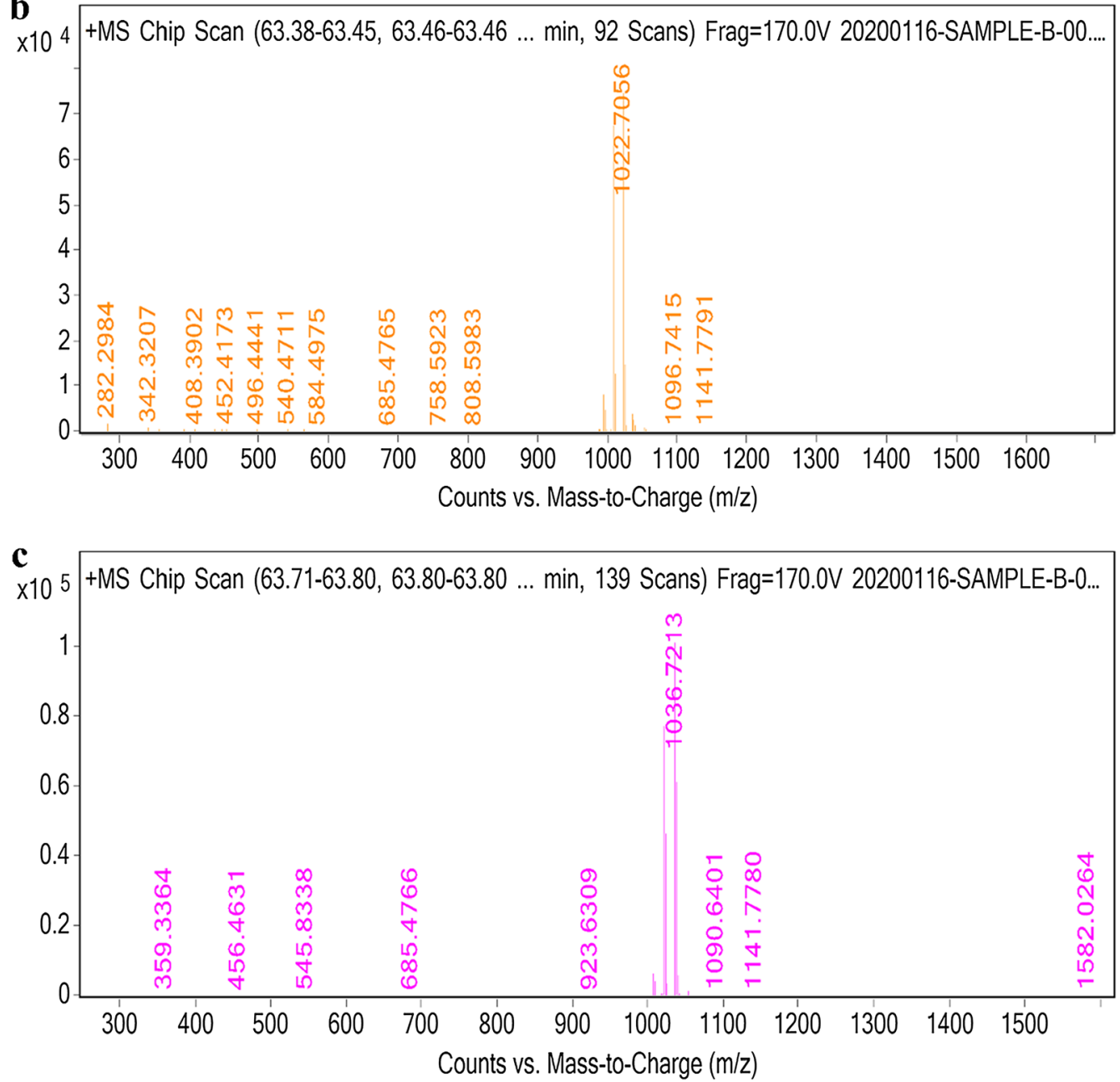

Fig. 7 Full ESI-MS scan of LC separated peak from dual gradient fraction (F5 80\% acetone $\mathrm{pH} 8$ ) in positive ion mode showing molecular ion [M $+\mathrm{H}$ ] of peaks at range of 62 to 64 min $\mathbf{a} \mathrm{C}_{12}$-Surfactin $\mathbf{b} \mathrm{C}_{14}$-Surfactin $\mathbf{c} \mathrm{C}_{15}$-Surfactin 
Table 3 Antimicrobial activity of purified surfactin against selected Gram-positive including antibiotic-resistant food born pathogen

\begin{tabular}{lll}
\hline Indicator Strains & \multicolumn{2}{l}{ Antimicrobial activity (AU/ml) } \\
\cline { 2 - 3 } & Lipopeptide & Lipopeptide* \\
\hline B. cereus NCIM 2703 & 32,000 & 16,000 \\
B. cereus ATCC 10,876 & 16,000 & 16,000 \\
S. aureus NCIM 2654 & 16,000 & 200 \\
S. aureus (MRSA) & 800 & 400 \\
\hline
\end{tabular}

Comparative chromatographic techniques have been used for the purification of lipopeptides from the partially purified extract. Silica gel, size exclusion column chromatography method could not separate families of lipopeptides (Iturin or surfactin). Hence, an individual family of surfactin and iturin was purified at homogeneity by using dual gradient chromatography and identified by the RP-HPLC method. The families of lipopeptides and their isoforms produced by Bacillus spp. can be poorly separated by using only solvent gradients such as acetone or methanol due to their similar polarity (Dhanarajan et al. 2015; Zhao et al. 2016). The TLC, FTIR, and biochemical characterization of the antimicrobial agent from B. velezensis SK identified amphipathic, $\mathrm{pH}$, and thermo-stable cyclic lipopeptides (Detail physiochemical character mention in Additional file 1: Table S6). In addition, FTIR analysis of various partial purified and purified fractions with surfactin revealed the purity of surfactin, when compared to standard surfactin. However, the antimicrobial activity of purified lipopeptide did not affect by organics solvents (methanol, ethanol, acetone, chloroform, and ethyl acetate as used during purification), which indicates their solvent stability (Additional file 1: Table S6). Further, in-vitro bioautography of TLC separated surfactin confirmed its antagonistic activity against food-born pathogen B. cereus NCIM 2703. Altogether, antimicrobial activity results by various methods confirmed that the HP-20 crude extract and purified surfactin could inhibit the growth of E.coli, P. vulgaris, $S$. aureus, and B. cereus including streptomycin-resistant strains. LC-ESI-MS analysis of partially purified HP-20 extract and dual gradient purified fractions showed $B$. velezensis SK mainly produces a surfactin group of lipopeptides with a small amount of iturin. $B$. velezensis SK surfactin mainly comprises five homologues of varying $\beta$-hydroxy fatty acid with most abundant $\mathrm{C}_{15}$-Surfactin (m/z 1036).

In summary, this study resulted in the isolation of potent antibacterial surfactin producing new strain $B$. velezensis SK. The new strain and its concomitant antimicrobial potential of surfactin production could be useful to combat drug-resistant human pathogens and food-born pathogen B.cereus ATCC 10,876, responsible to cause diseases such as bacteremia, pneumonia in immune-compromised patients. Similarly, isolated $B$. velezensis SK strain could be a used as probiotic, a similar type of $B$. velezensis CPA1-1 strain has been reported as a probiotic in aquaculture industries ( $\mathrm{Li}$ et al., 2020a, b). Thus, the isolated lipopeptide producer strain could be useful at a commercial level due to its potential to produce lipopeptide.

\section{Supplementary Information}

The online version contains supplementary material available at https://doi. org/10.1186/s13568-022-01348-3.

Additional file 1. Additional datasets of figures and tables supporting conclusions of this article includes in additional information.

\section{Acknowledgements}

KDS gratefully acknowledges University Grants Commission, New Delhi for financial support under the UGC-SAP-DRS Phase-II scheme sanctioned to Department of Biochemistry, Shivaji University, Kolhapur. SSB is thankful to SARTHI for providing CMSRF-2019 fellowship. Authors are very grateful to the Department of Microbiology, Shivaji University, Kolhapur and for extending the laboratory facilities to complete the investigation. Authors also thankful to Department of Botany, Shivaji University, Kolhapur for proving HPLC facility.

\section{Authors' contributions}

KDS conceived, designed and coordinated the study, validated the results, wrote and reviewed the manuscript; SSB designed and conducted experiments, analysed data and wrote initial manuscript; SGG provided technical assistant in HPLC analysis. All authors read and approved the final manuscript.

\section{Funding}

Not applicable.

\section{Data availability}

All relevant data are within the paper and its additional information files, and 16 s rRNA data have been deposited in "GenBank" with the accession codes MK007327.1 are fully available.

\section{Declarations}

\section{Ethics approval and consent to participate}

This article does not contain any studies with animals performed by any of the authors.

Consent for publication

Not applicable.

Competing interests

All authors declare that no competing interests exist.

\section{Author details}

${ }^{1}$ Department of Microbiology, Shivaji University, Kolhapur 416004, Maharashtra, India. ${ }^{2}$ Structural Bioinformatics Unit, Department of Biochemistry, Shivaji University, Kolhapur 416004, Maharashtra, India. ${ }^{3}$ Department of Botany,

Shivaji University, Kolhapur 416004, Maharashtra, India.

Received: 3 January 2022 Accepted: 16 January 2022

Published online: 27 January 2022 


\section{References}

Al-Ajlani MM, Sheikh MA, Ahmad Z, Hasnain S (2007) Production of surfactin from Bacillus subtilis MZ-7 grown on pharmamedia commercial medium. Microb Cell Fact 6:17

Alekshun MN, Levy SB (2007) Molecular Mechanisms of Antibacterial Multidrug Resistance. Cell 128(6):1037-1050

Balan SS, Kumar CG, Jayalakshmi S (2017) Aneurinifactin, a new lipopeptide biosurfactant produced by a marine Aneurinibacillus aneurinilyticus SBP-11 isolated from Gulf of Mannar: Purification, characterization and its biological evaluation. Microbiol Res 194:1-9

Balouiri M, Sadiki M, Ibnsouda SK (2016) Methods for in vitro evaluating antimicrobial activity: A review. J Pharm Anal 6(2):71-79

Chen L, Wang N, Wang X, Hu J, Wang S (2010) Characterization of two antifungal lipopeptides produced by Bacillus amyloliquefaciens SH-B10. Bioresour Technol 101(22):8822-8827

Chen M, Wang J, Liu B, Zhu Y, Xiao R, Yang W, Ge C, Chen Z (2020) Biocontrol of tomato bacterial wilt by the new strain Bacillus velezensis FJAT-46737 and its lipopeptides. BMC Microbiol 20(1):160

Chopra L, Singh G, Choudhary V, Sahoo DK (2014) Sonorensin: an antimicrobial peptide, belonging to the heterocycloanthracin subfamily of bacteriocins, from a new marine isolate, Bacillus sonorensis MT93. Appl Environ Microbiol 80(10):2981-2990

Chun J, Lee JH, Jung Y, Kim M, Kim S, Kim BK, Lim YW (2007) EzTaxon: a webbased tool for the identification of prokaryotes based on $16 \mathrm{~S}$ ribosomal RNA gene sequences. Int J Syst Evol Microbiol 57(10):2259-2261

CLSI, Standard for Performing Antimicrobial Susceptibility Testing. 29th ed. CLSI Supplement M100. Wayne, PA; Clinical laboratory standard institute.

Dang Y, Zhao F, Liu X, Fan X, Huang R, Gao W, Wang S, Yang C (2019) Enhanced production of antifungal lipopeptide iturin A by Bacillus amyloliquefaciens LL3 through metabolic engineering and culture conditions optimization. Microb Cell Fact 18(1):68

Das P, Mukherjee S, Sen R (2008) Antimicrobial potential of a lipopeptide biosurfactant derived from a marine Bacillus circulans. J Appl Microbiol 104(6):1675-1684

De Faria AF, d, Teodoro-Martinez DS, Barbosa GNdO, Serrano Silva BGV, Garcia IJS, Tótola MR, Eberlin N, Grossman M, Alves OL, Durrant LR, (2011) Production and structural characterization of surfactin (C14/Leu7) produced by Bacillus subtilis isolate LSFM-05 grown on raw glycerol from the biodiesel industry. Process Biochem 46(10):1951-1957

De Souza CG, Martins FICC, Zocolo GJ, Figueiredo JEF, Canuto KM, de Brito ES (2018) Simultaneous quantification of lipopeptide isoforms by UPLC-MS in the fermentation broth from Bacillus subtilis CNPMS22. Anal Bioanal Chem 410(26):6827-6836

Detns RC, Taken S, Co FS, Smith FC, Co Titrim F (1959) Use of dinitrosalicylic acid reagent for determination of reducing sugar. Anal Chem 31:426-428

Dewanjee S, Gangopadhyay M, Bhattacharya N (2015) Bioautography and its scope in the field of natural product chemistry. J Pharm Anal 5(2):75-84

Dhanarajan G, Rangarajan V, Sen R (2015) Dual gradient macroporous resin column chromatography for concurrent separation and purification of three families of marine bacterial lipopeptides from cell free broth. Sep Purif Technol 143:72-79

Dhanarajan G, Rangarajan V, Sridhar PR, Sen R (2016) Development and Scaleup of an Efficient and Green Process for HPLC purification of antimicrobial homologues of commercially important microbial lipopeptides. ACS Sustain Chem Eng 4:6638-6646

Ganesan P, Reegan AD, David RHA, Gandhi MR, Paulraj MG, Al-Dhabi NA, Ignacimuthu S (2017) Antimicrobial activity of some actinomycetes from Western Ghats of Tamil Nadu. India Alexandria J Med 53(2):101-110

Goswami M, Deka S (2019) Biosurfactant production by a rhizosphere bacteria Bacillus altitudinis MS16 and its promising emulsification and antifungal activity. Colloids Surf B Biointerfaces 178:285-296

Grady EN, Macdonald J, Ho MT, Weselowski B, Mcdowell T, Solomon O, Renaud J, Yuan ZC (2019) Characterization and complete genome analysis of the surfactin-producing, plant-protecting bacterium Bacillus velezensis. BMC Microbiol 9D-6:1-14

Guo Y, Huang E, Yuan C, Zhang L, Yousef AE (2012) Isolation of a Paenibacillus sp Strain and structural elucidation of its broad-spectrum lipopeptide antibiotic. Appl Environ Microbiol 78(9):3156-3165

Hassan M, Kjos M, Nes IF, Diep DB, Lotfipour F (2012) Natural antimicrobial peptides from bacteria: Characteristics and potential applications to fight against antibiotic resistance. J Appl Microbiol 113(4):723-736
Hmidet N, BenAyed H, Jacques P, Nasri M (2017) Enhancement of Surfactin and Fengycin Production by Bacillus mojavensis A21: Application for Diesel Biodegradation. Biomed Res Int 67:5893123

Jha SS, Joshi SJ, Geetha SJ (2016) Lipopeptide production by Bacillus subtilis R1 and its possible applications. Braz J Microbiol 47(4):955-964

Korenblum E, de Araujo LV, Guimarães CR, de Souza LM, Sassaki G, Abreu F, Nitschke M, Lins U, Freire DM, Barreto-Bergter E, Seldin L (2012) Purification and characterization of a surfactin-like molecule produced by Bacillus sp H2O-1 and its antagonistic effect against sulfate reducing bacteria. BMC Microbiol 12:252

Kulimushi PZ, Arias AA, Franzil L, Steels S, Ongena M (2017) Stimulation of Fengycin-Type Antifungal Lipopeptides in Bacillus amyloliquefaciens in the Presence of the Maize Fungal Pathogen Rhizomucor variabilis. Front Microbiol 8:850. https://doi.org/10.3389/fmicb.2017.00850

Kumar A, Saini P, Shrivastava JN (2009) Production of peptide antifungal antibiotic and biocontrol activity of Bacillus subtilis. Indian J Exp Biol 47(1):57-62

Kumar S, Stecher G, Tamura K (2016) MEGA7: Molecular Evolutionary Genetics Analysis Version 7.0 for Bigger Datasets. Mol Biol Evol 33(7):1870-1874

Laverty G, Gorman SP, Gilmore BF (2011) The potential of antimicrobial peptides as biocides. Int J Mol Sc 12(10):6566-6596

Lee H, Churey JJ, Worobo RW (2008) Purification and structural characterization of bacillomycin F produced by a bacterial honey isolate active against Byssochlamys fulva H25. J Appl Microbiol 105(3):663-673

Li W, Rokni-Zadeh H, De Vleeschouwer M, Ghequire MG, Sinnaeve D, Xie GL, Rozenski J, Madder A, Martins JC, De Mot R (2013) The antimicrobial compound xantholysin defines a new group of Pseudomonas cyclic lipopeptides. PLoS ONE 8(5):e62946

Li FZ, Zeng YJ, Zong MH, Yang JG, Lou WY (2020a) Bioprospecting of a novel endophytic Bacillus velezensis FZO6 from leaves of Camellia assamica: Production of three groups of lipopeptides and the inhibition against food spoilage microorganisms. J Biotechnol 323:42-53

Li X, Gao X, Zhang S, Jiang Z, Yang H, Liu X, Jiang Q, Zhang X (2020b) Characterization of a Bacillus velezensis with antibacterial activity and inhibitory effect on common aquatic pathogens. Aquaculture 523:735165

Liu C, Sheng J, Chen L, Zheng Y, Lee DY, Yang Y, Xu M, Shen L (2015) Biocontrol Activity of Bacillus subtilis Isolated from Agaricus bisporus Mushroom Compost Against Pathogenic Fungi. J Agric Food Chem 63(26):6009-6018

Liu Y, Teng K, Wang T, Dong E, Zhang M, Tao Y, Zhong J (2020) Antimicrobial Bacillus velezensis HC6: production of three kinds of lipopeptides and biocontrol potential in maize. J Appl Microbiol 128(1):242-254

Malfanova N, Franzil L, Lugtenberg B, Chebotar V, Ongena M (2012) Cyclic lipopeptide profile of the plant-beneficial endophytic bacterium Bacillus subtilis HC8. Arch Microbiol 194(11):893-899

Mukherjee S, Das P, Sen R (2009) Rapid quantification of a microbial surfactant by a simple turbidometric method. J Microbiol Methods 76(1):38-42

Nadaf NH, Parulekar RS, Patil RS, Gade TK, Momin AA, Waghmare SR, Dhanavade MJ, Arvindekar AU, Sonawane KD (2018) Biofilm inhibition mechanism from extract of Hymenocallis littoralis leaves. J Ethnopharmacol 222:121-132

Nair AS, Al-Bahry S, Sivakumar N (2020) Co-production of microbial lipids and biosurfactant from waste office paper hydrolysate using a novel strain Bacillus velezensis ASN1. Biomass Conv Bioref 10(2):383-391

Nanjundan J, Ramasamy R, Uthandi S, Ponnusamy M (2019) Antimicrobial activity and spectroscopic characterization of surfactin class of lipopeptides from Bacillus amyloliquefaciens SR1. Microb Pthog 128:374-380

Ohno A, Ano T, Shoda M (1995) Production of a lipopeptide antibiotic, surfactin, by recombinant Bacillus subtilis in solid state fermentation. Biotechnol Bioeng 47(2):209-214

Ongena M, Jacques P (2008) Bacillus lipopeptides: versatile weapons for plant disease biocontrol. Trends Microbiol 16(3):115-125

Palazzini JM, Dunlap CA, Bowman MJ, Chulze SN (2016) Bacillus velezensis RC 218 as a biocontrol agent to reduce Fusarium head blight and deoxynivalenol accumulation: Genome sequencing and secondary metabolite cluster profiles. Microbiol Res 192:30-36

Parulekar RS, Sonawane KD (2018a) Insights into the antibiotic resistance and inhibition mechanism of aminoglycoside phosphotransferase from Bacillus cereus : In silico and in vitro perspective. J Cell Biochem 119(11):9444-9461

Parulekar RS, Sonawane KD (2018b) Molecular modeling studies to explore the binding affinity of virtually screened inhibitor toward different 
aminoglycoside kinases from diverse MDR strains. J Cell Biochem 119(3):2679-2695

Parulekar RS, Barale SS, Sonawane KD (2019) Antibiotic resistance and inhibition mechanism of novel aminoglycoside phosphotransferase APH (5) from B. subtilis subsp. subtilis strain RK. Braz J Microbiol 50(4):887-898

Raaijmakers JM, De Bruijn I, Nybroe O, Ongena M (2010) Natural functions of lipopeptides from Bacillus and Pseudomonas: more than surfactants and antibiotics. FEMS Microbiol Rev 34(6):1037-1062

Rabbee MF, Ali MS, Choi J, Hwang BS, Jeong SC, Baek KH (2019) Bacillus velezensis: A Valuable Member of Bioactive Molecules within Plant Microbiomes. Molecules 24(6):1046

Ramachandran R, Shrivastava M, Narayanan NN, Thakur RL, Chakrabarti A, Roy U (2018) Evaluation of Antifungal Efficacy of Three New Cyclic Lipopeptides of the Class Bacillomycin from Bacillus subtilis RLID 121. Antimicrob Agents Chemother 62(1):e01457-e1517

Rangarajan V, Clarke KG (2015) Process development and intensification for enhanced production of Bacillus lipopeptides. Biotechnol Genet Eng Rev $31: 46-68$

Rangarajan V, Clarke KG (2016) Towards bacterial lipopeptide products for specific applications - a review of appropriate downstream processing schemes. Process Biochem 51:2176-2185

Rangarajan V, Dhanarajan G, Sen R (2015) Bioprocess design for selective enhancement of fengycin production by a marine isolate Bacillus megaterium. Biochem Eng J 99:147-155

Romano A, Vitullo D, Senatore M, Lima G, Lanzotti V (2013) Antifungal cyclic lipopeptides from Bacillus amyloliquefaciens strain BO5A. J Nat Prod 76(11):2019-2025

Roy RN, Lomakin IB, Gagnon MG, Steitz TA (2015) The mechanism of inhibition of protein synthesis by the proline-rich peptide oncocin. Nat Struct Mol Biol 22(6):466-469

Ruiz-García C, Béjar V, Martínez-Checa F, Llamas I, Quesada E (2005) Bacillus velezensis sp nov a surfactant-producing bacterium isolated from the river Vélez in Málaga, southern Spain. Int J Syst Evol Microbiol 55(1):191-195

Sarwar A, Nadeem M, Imran M, Iqbal M (2018) Biocontrol activity of surfactin A purified from Bacillus $\mathrm{NH}-100$ and $\mathrm{NH}-217$ against rice bakanae disease. Microbiol Res 209:1-13

Sastalla I, Fattah R, Coppage N, Nandy P, Crown D, Pomerantsev AP, Leppla SH (2013) The Bacillus cereus $\mathrm{Hbl}$ and Nhe tripartite enterotoxin components assemble sequentially on the surface of target cells and are not interchangeable. PLoS ONE 8(10):e76955

Seghal Kiran G, Anto Thomas TJ, Sabarathnam SB, Lipton AP (2010) Optimization and characterization of a new lipopeptide biosurfactant produced by marine Brevibacterium aureum MSA13 in solid state culture. Bioresour Technol 101(7):2389-2396

Sharma D, Mandal SM, Kumari MR (2014) Purification and characterization of a novel lipopeptide from Streptomyces amritsarensis sp nov active against methicillin-resistant Staphylococcus aureus. AMB Express 4:50

Sharma R, Singh J, Verma N (2018) Production, characterization and environmental applications of biosurfactants from Bacillus amyloliquefaciens and Bacillus subtilis. Biocatal Agric Biotechnol 16:132-139

Singh AK, Sharma P (2020) Disinfectant-like activity of lipopeptide biosurfactant produced by Bacillus tequilensis strain SDS21. Colloids Surf B Biointerfaces 185:110514

Smyth TJ, Rudden M, Tsaousi K, Marchant R, Banat IM (2014) Protocols for the Isolation and Analysis of Lipopeptides and Bioemulsifiers. In: McGenity T, Timmis K, Nogales B (eds) Hydrocarbon and Lipid Microbiology Protocols. Springer Protocols Handbooks, Springer, Heidelberg

Sumi CD, Yang BW, Yeo IC, Hahm YT (2015) Antimicrobial peptides of the genus Bacillus: a new era for antibiotics. Can J Microbiol 61(2):93-103

Varjani SJ, Upasani VN (2017) Critical review on biosurfactant analysis, purification and characterization using rhamnolipid as a model biosurfactant. Bioresour Technol 232:389-397

Waghmare SR, Randive SA, Jadhav DB, Nadaf NH, Parulekar RS, Sonawane KD (2019) Production of novel antimicrobial protein from Bacillus licheniformis strain JS and its application against antibiotic-resistant pathogens. J Proteins Proteom 10(1):17-22

Wang S, Sun L, Zhang W, Chi F, Hao X, Bian J, Li Y (2020) Bacillus velezensis BM21, a potential and efficient biocontrol agent in control of corn stalk rot caused by Fusarium graminearum. Egypt J Biol Pest Control 30:9
Willenbacher J, Yeremchuk W, Mohr T, Syldatk C, Hausmann R (2015) Enhancement of Surfactin yield by improving the medium composition and fermentation process. AMB Express 5:57

Wright GD (2007) The antibiotic resistome: the nexus of chemical and genetic diversity. Nat Rev Microbiol 5:175-186

Wu J, Xu G, Jin Y, Sun C, Zhou L, Lin G, Xu R, Wei L, Fei H, Wang D, Chen J, Lv Z, Liu K (2018) Isolation and characterization of Bacillus sp GFP-2, a novel Bacillus strain with antimicrobial activities, from Whitespotted bamboo shark intestine. AMB Expr 8:84

Yang X, Huang E, Yuan C, Zhang L, Yousef AE (2016) Isolation and Structural Elucidation of Brevibacillin, an Antimicrobial Lipopeptide from Brevibacillus laterosporus That Combats Drug-Resistant Gram-Positive Bacteria. Appl Environ Microbiol 82(9):2763-2772

Ye M, Tang X, Yang R, Zhang H, Li F, Tao F, Li F, Wang Z (2018) Characteristics and Application of a Novel Species of Bacillus: Bacillus velezensis. ACS Chem Biol 13(3):500-505

Zhao X, Kuipers OP (2016) Identification and classification of known and putative antimicrobial compounds produced by a wide variety of Bacillales species. BMC Genomics 17(1):882

Zhao H, Shao D, Jiang C, Shi J, Li Q, Huang Q, Rajoka MSR, Yang H, Jin M (2017) Biological activity of lipopeptides from Bacillus. Appl Microbiol Biotechnol 101(15):5951-5960

Zhao P, Xue Y, Gao W, Li J, Xiangyang Z, Dongliao F, Shuxiao F, Xuefei B, Yanjun Z, Ping L (2018) Actinobacteria-Derived peptide antibiotics since 2000. Peptides 103:48-59

Zheng C, Wang M, Wang Y, Huang Z (2012) Optimization of biosurfactantmediated oil extraction from oil sludge. Bioresour Technol 110:338-342

\section{Publisher's Note}

Springer Nature remains neutral with regard to jurisdictional claims in published maps and institutional affiliations.

\section{Submit your manuscript to a SpringerOpen ${ }^{\circ}$ journal and benefit from:}

- Convenient online submission

- Rigorous peer review

- Open access: articles freely available online

- High visibility within the field

- Retaining the copyright to your article

Submit your next manuscript at $\gg$ springeropen.com 